\title{
Targeting strategies for oxaliplatin-induced peripheral neuropathy: clinical syndrome, molecular basis, and drug development
}

\author{
Yang Yang ${ }^{1,2,3,4^{*}+} \oplus$, Bing Zhao ${ }^{1,2+}$, Xuejiao Gao ${ }^{1,2+}$, Jinbing Sun ${ }^{5}$, Juan Ye $\mathrm{Y}^{1,2}$, Jun Li ${ }^{6}$ and Peng Cao ${ }^{1,2,7^{*}}$
}

\begin{abstract}
Oxaliplatin (OHP)-induced peripheral neurotoxicity (OIPN) is a severe clinical problem and potentially permanent side effect of cancer treatment. For the management of OIPN, accurate diagnosis and understanding of significant risk factors including genetic vulnerability are essential to improve knowledge regarding the prevalence and incidence of OIPN as well as enhance strategies for the prevention and treatment of OIPN. The molecular mechanisms underlying OIPN are complex, with multi-targets and various cells causing neuropathy. Furthermore, mechanisms of OIPN can reinforce each other, and combination therapies may be required for effective management. However, despite intense investigation in preclinical and clinical studies, no preventive therapies have shown significant clinical efficacy, and the established treatment for painful OIPN is limited. Duloxetine is the only agent currently recommended by the American Society of Clinical Oncology. The present article summarizes the most recent advances in the field of studies on OIPN, the overview of the clinical syndrome, molecular basis, therapy development, and outlook of future drug candidates. Importantly, closer links between clinical pain management teams and oncology will advance the effectiveness of OIPN treatment, and the continued close collaboration between preclinical and clinical research will facilitate the development of novel prevention and treatments for OIPN.
\end{abstract}

Keywords: Oxaliplatin-induced peripheral neuropathy, Clinical syndrome, Molecular basis, Drug development, Oxidative stress, Gut microbiota

\section{Background}

Chemotherapy-induced peripheral neuropathy (CIPN) is a serious clinical problem caused by cytotoxic drugs that cause different pathologic insults to neurons, including platinum, taxanes, proteasome inhibitors, vinca alkaloids, and immunomodulatory drugs with impairment progress in peripheral and central nerve systems, and presents in a "glove-and-stocking" symptom [1] (Fig. 1).

\footnotetext{
*Correspondence: young1570@126.com; cao_peng@njucm.edu.cn †Yang Yang, Bing Zhao and Xuejiao Gao contributed equally to this work as co-first authors.

${ }^{1}$ Affiliated Hospital of Integrated Traditional Chinese and Western Medicine, Nanjing University of Chinese Medicine, 100\#, Hongshan Road, Nanjing 210028, Jiangsu, China

Full list of author information is available at the end of the article
}

Regarding overall neurotoxic chemotherapy, the prevalence of CIPN is approximately $68 \%$ at 1 month, reducing to $60 \%$ at 3 months and $30 \%$ at 6 months or more [2]. The type of chemotherapy influences the risk of developing CIPN and a wide range of occurrences are reported depending on different CIPN assessment and dosing regimens (Table 1).

Oxaliplatin (OHP) is the most prominent neurotoxic chemotherapy agent that interferes with tumor cell proliferation by forming DNA-platinum adducts, which lead to the destruction of cancer cells [7]. With the increasing clinical use of OHP, inevitably adverse reactions have been reported, with the major side effects being peripheral neurotoxicity, myelosuppression, and gastrointestinal reactions $[8,9]$. These side effects of OHP 


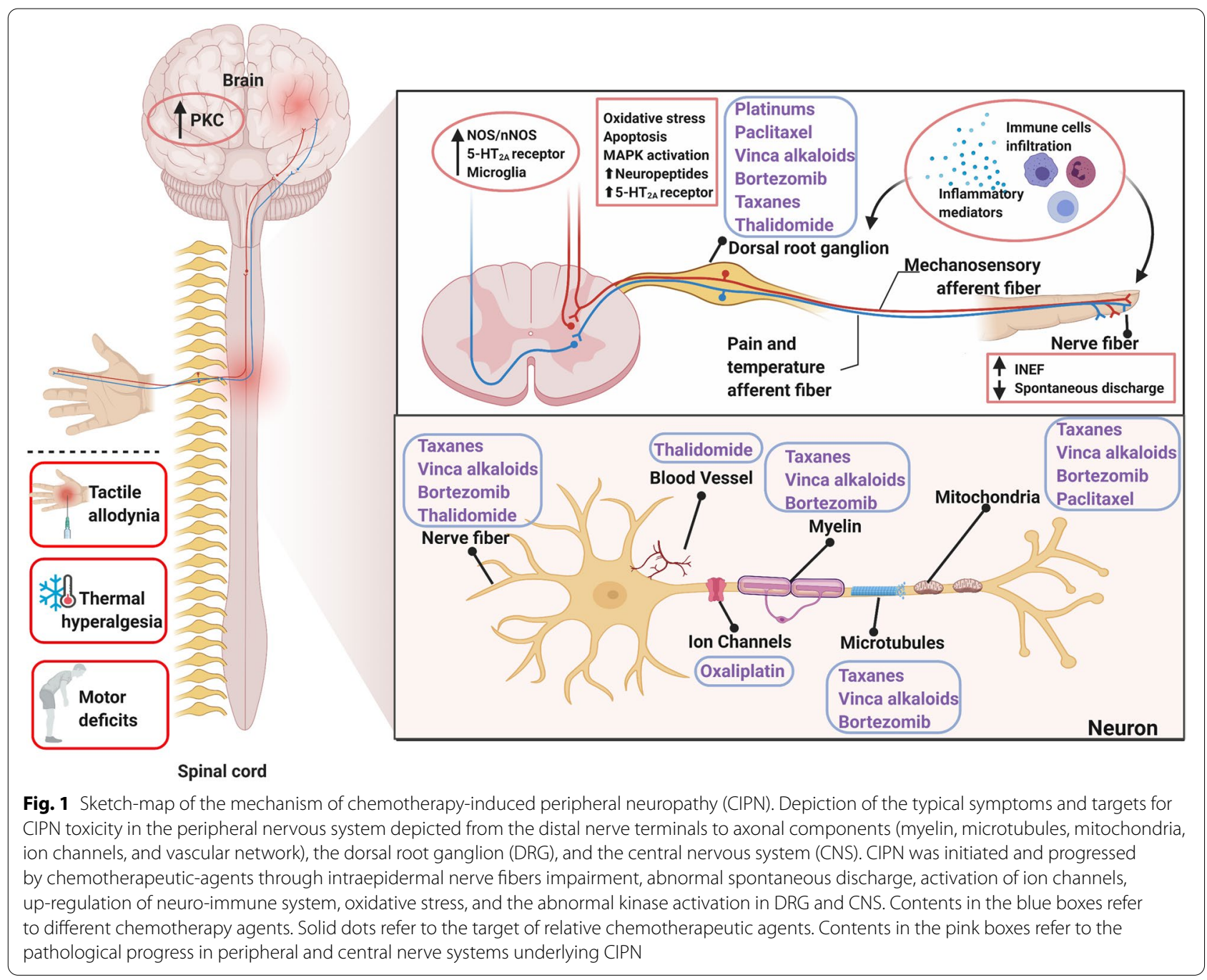

Table 1 Chemotherapeutics and the incidence or prevalence of reported neuropathies

\begin{tabular}{|c|c|c|c|}
\hline Chemotherapy & Class & $\begin{array}{l}\text { Approximate incidence/prevalence } \\
\text { of CIPN (\%) }\end{array}$ & References \\
\hline Oxaliplatin & Platinum-based chemotherapeutics & $\begin{array}{l}\text { Acute: 85-96; chronic wide range: } \\
\text { 40-93 }\end{array}$ & [3] \\
\hline Cisplatin & & $12-85$ & \\
\hline Paclitaxel & Taxanes & $61-92$ & {$[2,4]$} \\
\hline Bortezomib & Proteasome inhibitor & $47-80$ & \\
\hline Vincristine & Vinca alkaloids & $14-70$ & {$[5]$} \\
\hline Thalidomide & Immunomodulatory drugs & $21-50$ & [6] \\
\hline
\end{tabular}

Data are mainly from randomized controlled trials or prospective cohort studies CIPN Chemotherapy-induced peripheral neuropathy

may result in the terminations of treatment plans and a reduction in the compliance of colorectal cancer (CRC) patients during the treatment. This is important because OHP-induced peripheral neuropathy (OIPN) is the most common side effect associated with OHP dose-limiting toxicity [10]. In this paper, we reviewed the main progress of OIPN, focusing on the clinical syndrome, its molecular basis, and drug development. 


\section{The clinical syndrome: classification} and characteristics, clinical diagnosis, risk factors, and genetic polymorphisms with OIPN Classification and characteristics

OHP-induced neurotoxicity can be divided into two distinct forms, acute and chronic, according to the incidence, symptoms, duration, mechanisms, and other clinical features. Acute OIPN, triggered mainly by cold stimulation, occurs in $85-96 \%$ of patients within hours of infusion and lasts for the following 7 days $[10,11]$. It is characterized by cold-sensitive peripheral paresthesia (hands and feet dysesthesia and paresthesia) and motor symptoms (e.g., prolonged muscular contractions, tetanic spasms, and fasciculations) [12] (Fig. 2). The most important mechanism involved in acute OIPN is the transient impairment of the $\mathrm{Na}_{\mathrm{v}}$ channel activation of the dorsal root ganglion (DRG) sensory neurons and nerve hyperexcitability, due to oxalate metabolites [13, 14] (Fig. 2). Furthermore, the degree of acute neuropathy seems to predict the development of chronic neurotoxicity [7]. The development of chronic OIPN is likely to occur at cumulative doses exceeding $780-850 \mathrm{mg} / \mathrm{m}^{2}$ (40-93\% incidence), and can even last for several years [7, 15-18]. Clinically, chronic OIPN may result in sensation loss and changes in proprioception that affect daily activities (Fig. 2). An important feature of chronic OIPN is the "coasting," in which approximately $60 \%$ of patients report longlasting neuropathic symptoms that significantly impair their quality of life after completing the last chemotherapy course $[11,19]$. This is an important factor in deciding termination of treatment because of the neurotic symptoms, which can lead to disability [20]. The main mechanism responsible for the observed permanent distal sensory loss is associated with mitochondrial damage, the death of sensory neurons (i.e., nerve cell necrosis), glia activation, and neuroinflammation [21] (Table 2).

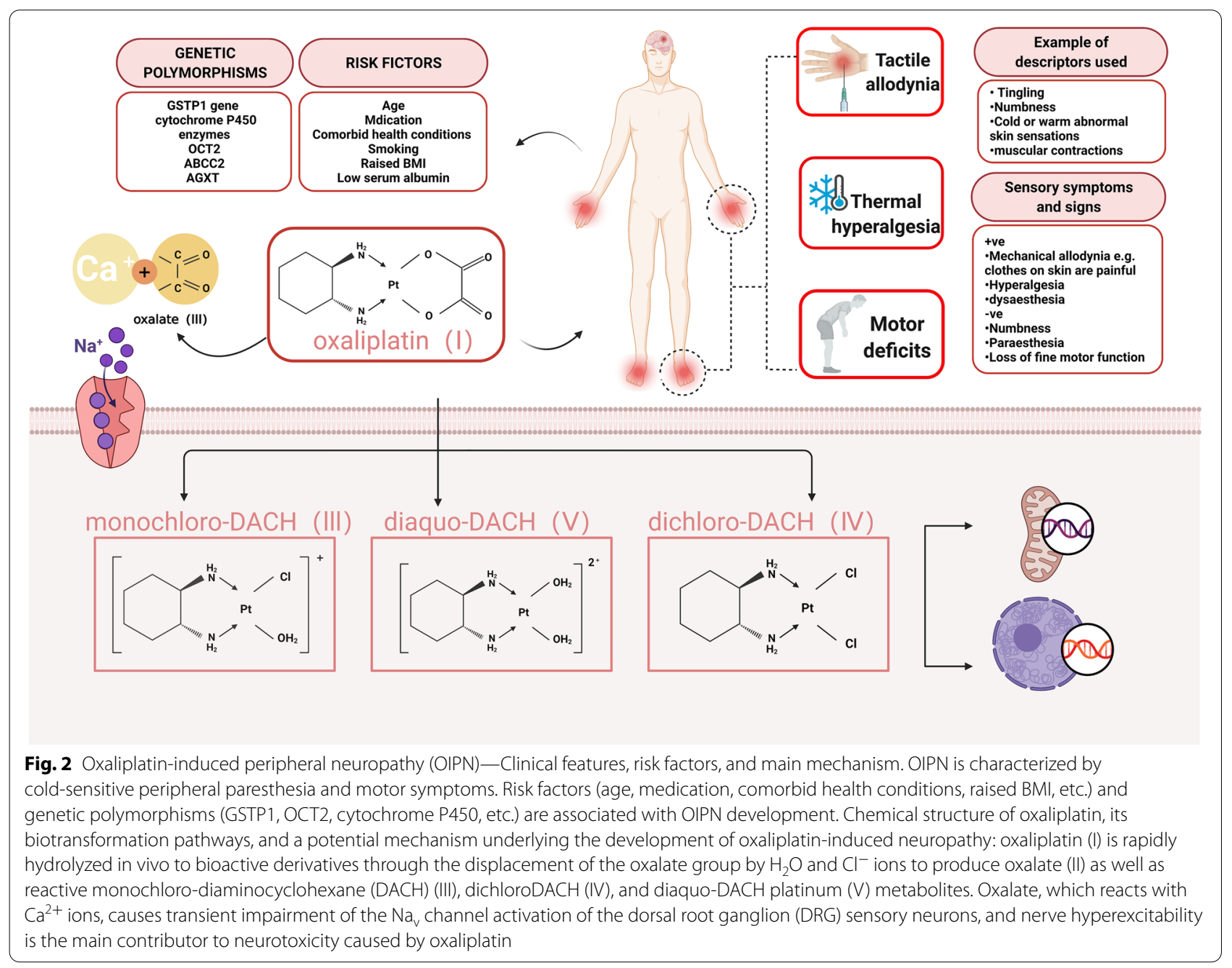


Table 2 Characteristics of acute and chronic OIPN

\begin{tabular}{|c|c|c|c|}
\hline Characteristics & Acute OIPN & Chronic OIPN & References \\
\hline Incidence rate & $85-96 \%$ & $40-93 \%$ & {$[7,10,11,15-18]$} \\
\hline Duration & $\begin{array}{l}\text { Within hours of infusion and last- } \\
\text { ing for the following } 7 \text { days }\end{array}$ & Within 6-12 months, or even lasting for 5 years & \\
\hline Typical feature & $\begin{array}{l}\text { Cold-sensitive peripheral pares- } \\
\text { thesia, motor symptoms }\end{array}$ & Acute OIPN symptoms and the "coasting" phenotype & {$[7,11,19]$} \\
\hline Mechanism & $\mathrm{Na}_{v}$ channel activation & $\begin{array}{l}\text { Sensory neurons death, mitochondrial damage, oxidative stress, } \\
\text { glia activation, and neuroinflammation, etc. }\end{array}$ & {$[13,14,21]$} \\
\hline
\end{tabular}

OIPN Oxaliplatin-induced peripheral neuropathy

\section{Clinical diagnosis}

Accurate assessment and diagnosis are important in the management and understanding of the epidemiology of OIPN. However, there is currently no widely accepted, standardized assessment approach for the diagnosis of CIPN per se. A preliminary diagnosis of OIPN can be made according to a combination of signs and clinical symptoms, quantitative sensory tests (QST), and electrophysiological measurements (EPM) [22]. Some of the grading scales usually used in clinical practice to evaluate peripheral neuropathy associated with chemotherapy include Total Neuropathy Score clinical version (TNSc), National Cancer Institute-Common Toxicity Criteria (NCI-CTC), modified Inflammatory Neuropathy Cause and Treatment (INCAT) group sensory sum score (mISS), European Organization for Research and Treatment of Cancer (EORTC) QLQ-C30, and CIPN (chemotherapy-induced peripheral neuropathy) 20 quality-of-life measures [23-27] (Table 3).

Furthermore, rapid non-invasive corneal confocal microscopy, LDI (laser Doppler imager) technology, and surface electromyography recording are also methods that can be used to confirm the diagnosis of CIPN in patients [22, 28-30] (Table 3). The combination of artificial intelligence (AI) with the traditional scales may be important in the management and understanding of the epidemiology of OIPN [31, 32]. While clinical examination is an important part of the assessment, it may pose some challenges in non-specialist settings, particularly where a more detailed sensory profiling is used for a definitive diagnosis $[33,34]$.

\section{Risk factors and genetic polymorphisms with OIPN}

OIPN has become an increasingly significant clinical issue among cancer survivors [35]. Identifying who is at higher risk of developing OIPN would thus be an important step forward. Although there may be some statistical bias introduced by the techniques used, studies using multivariate statistical modeling have identified several risk factors, including age, medication (cardiovascular medication especially beta-blockers and the use of opioids), comorbid health conditions, raised body mass index (BMI), smoking, low serum albumin, neurofilament light chains in plasma or serum samples, decreased creatinine clearance, and baseline neuropathy $[2,36,37]$ (Table 4, Fig. 2). It also may be possible to use detailed

Table 3 Tools used for assessing OIPN

\begin{tabular}{|c|c|c|}
\hline OIPN & Tools & References \\
\hline \multirow{8}{*}{$\begin{array}{l}\text { Current tools used for the } \\
\text { clinical diagnosis of OIPN }\end{array}$} & National Cancer Institute-Common Toxicity Criteria (NCI-CTC) & {$[23]$} \\
\hline & Total Neuropathy Score clinical version (TNSc) & {$[24]$} \\
\hline & Modified Inflammatory Neuropathy Cause and Treatment (INCAT) group sensory sum score (mISS) & {$[25]$} \\
\hline & European Organization for Research and Treatment of Cancer (EORTC) QLQ-C30 & {$[27]$} \\
\hline & CIPN (chemotherapy induced peripheral neuropathy) 20 quality-of-life measures & {$[26]$} \\
\hline & Skin biopsy and quantified intraepidermal nerve fiber density & {$[28,29]$} \\
\hline & LDI technology & {$[22]$} \\
\hline & Surface electromyography recording & {$[30]$} \\
\hline $\begin{array}{l}\text { Comments for the ideal } \\
\text { CIPN assessment tools }\end{array}$ & $\begin{array}{l}\text { Specific to CIPN; validated in different types of chemotherapy; easy for patients to understand and com- } \\
\text { plete; can be used in postal questionnaires as well as face to face; performs consistently in different settings; } \\
\text { requires minimal training in use and scoring; sensitive to change; detects CIPN early; and reliable with } \\
\text { minimal interrater variability }\end{array}$ & [2] \\
\hline
\end{tabular}

CIPN Chemotherapy-induced peripheral neuropathy, LDI Laser Doppler imager, OIPN Oxaliplatin-induced peripheral neuropathy 
Table 4 Risk factors and genetic polymorphisms associated with OIPN

\begin{tabular}{|c|c|c|}
\hline OIPN & Comments & Reference \\
\hline \multirow[t]{5}{*}{$\begin{array}{l}\text { Risk factors associ- } \\
\text { ated with OIPN }\end{array}$} & $\begin{array}{l}\text { Age; comorbid health conditions: decreased creatinine clearance, smoking, etc.; raised BMl; low serum albumin; and } \\
\text { baseline neuropathy }\end{array}$ & {$[2,4,41]$} \\
\hline & Medication: cardiovascular especially beta blockers; use of opioids & {$[42,43]$} \\
\hline & Quantitative sensory testing deficits in patients & {$[38,39]$} \\
\hline & Thermal hyperalgesia & {$[40]$} \\
\hline & Neurofilament light chains in plasma or serum samples & {$[36,37]$} \\
\hline \multirow{3}{*}{$\begin{array}{l}\text { Genetic polymor- } \\
\text { phisms associated } \\
\text { with OIPN }\end{array}$} & GSTP1 gene (lle105Val polymorphism), cytochrome P450 enzymes, OCT2, ABCC2, and AGXT & {$[44-50]$} \\
\hline & SCN4A (rs2302237); SCN10A (rs1263292) associated with an increased incidence of acute oxaliplatin-induced CIPN & {$[51]$} \\
\hline & SCN9A (rs6746030) protected against severe oxaliplatin-induced CIPN & {$[52]$} \\
\hline
\end{tabular}

ABCC2 ATP binding cassette subfamily C member 2, AGXT Alanine glyoxylate aminotransferase, BMI Body mass index, CIPN Chemotherapy-induced peripheral neuropathy, GSTP1 Glutathione S-transferase pi 1, OCT2 Organic cation transporter 2, OIPN Oxaliplatin-induced peripheral neuropathy, SCN10A Sodium channel protein type 10 subunit alpha, SCN4A Sodium channel protein type 4 subunit alpha, SCN9A Sodium channel protein type 9 subunit alpha

phenotyping (QST identified subclinical deficits, thermal hyperalgesia, and individuals more sensitive to chemotherapy) to identify preexisting vulnerabilities for developing OIPN [38-40].

Genetic risk factors may be relevant for OIPN development, both in clinical settings and rodent models [53, 54]. It was suggested that polymorphisms of glutathione transferases (Ile105Val polymorphism of the GSTP1 gene), ATP binding cassette transporters, OCT2, cytochrome P450 enzymes, polymorphism of ABCC2 (ATP binding cassette subfamily $\mathrm{C}$ member 2 ), and AGXT (alanine glyoxylate aminotransferase) may be involved in the development of OIPN [44-50]. The development of acute OIPN was altered in patients with single-nucleotide polymorphisms in the SCNA genes encoding selected $\mathrm{Na}_{\mathrm{v}}$ channels (Table 4, Fig. 2) [51, 52]. As mentioned, these genetic risk factors can influence the absorption and metabolism of OHP, which are associated with OIPN formation. Moreover, genotypic profiles of CIPN patients and the knowledge of genetic susceptibility needs to be incorporated into clinical trials.

\section{The molecular basis}

The clinical features of OIPN provide important clues in the understanding of the basic molecular mechanisms of its onset. It is noteworthy that the mechanisms of acute and chronic OIPN are not identical. For acute OIPN, the dysfunction of ion channels, OCT protein, and glial cells are involved in the acute pain, whereas the main mechanisms relevant to chronic OIPN are nuclear DNA damage, oxidative stress-induced mitochondrial damage, glia activation-related neuroinflammation, and gut microbiota-induced inflammation (Fig. 3, Table 5). Mechanisms relying on the unique structure and function of the neurons need emphasis. The treatment of neuropathy should be modified with the discovery of new mechanisms.

\section{Ion channels dysfunction $\mathrm{Na}^{+}$channel}

The $\mathrm{Na}^{+}$channels play a core role in OHP-induced cold hyperalgesia [55]. Moreover, acute OHP-induced aggravation of cold hypersensitivity can be relieved by the administration of $\mathrm{Na}^{+}$blockers (lidocaine, mexiletine, carbamazepine, etc.) [56, 105]. OHP can delay $\mathrm{Na}^{+}$channels inactivation, which may be enhanced by exposure to cold [56]. Accumulation of OHP metabolite oxalate severed as a calcium chelator is thought to cause acute neurotoxicity. It can affect the functional properties of the $\mathrm{Na}^{+}$channels resulting in a prolonged open state of the $\mathrm{Na}^{+}$channels and hyperexcitability of the DRG sensory neurons [12, 57]. Furthermore, 78\% of chronic OIPN patients showed abnormalities in $\mathrm{Na}^{+}$ channels in clinical studies of chronic OIPN [45].

\section{$K^{+}$channel}

The $\mathrm{K}^{+}$channels are involved in regulating sensory neuronal pain and excitability [106]. It was demonstrated that OHP-induced neuropathy can induce functional abnormalities by increasing the pro-excitatory $\mathrm{K}^{+}$channels expression, such as the hyperpolarization-activated channels (HCNs) [59]. Furthermore, it was observed that OHP decreased the expression of the two-pore domain $\mathrm{K}^{+}$channels (TWIK-Related $\mathrm{K}^{+}$ Channel 1 (TREK-1) and TWIK-related arachidonic acid-stimulated $\mathrm{K}^{+}$channel (TRAAK)) in the DRG of rodents [107]. The activator of TREK-1 and TRAAK (riluzole) prevents OHP-induced motor and sensory deficits and attenuates the $\mathrm{OPH}$-induced depressionlike symptoms [60, 61]. While a slight association between OIPN and CAG repeat polymorphisms in the potassium channel SK3 (KCNN3 gene) gene was shown in a preclinical model, this was not demonstrated clinically [62]. Moreover, activation of slow axonal 


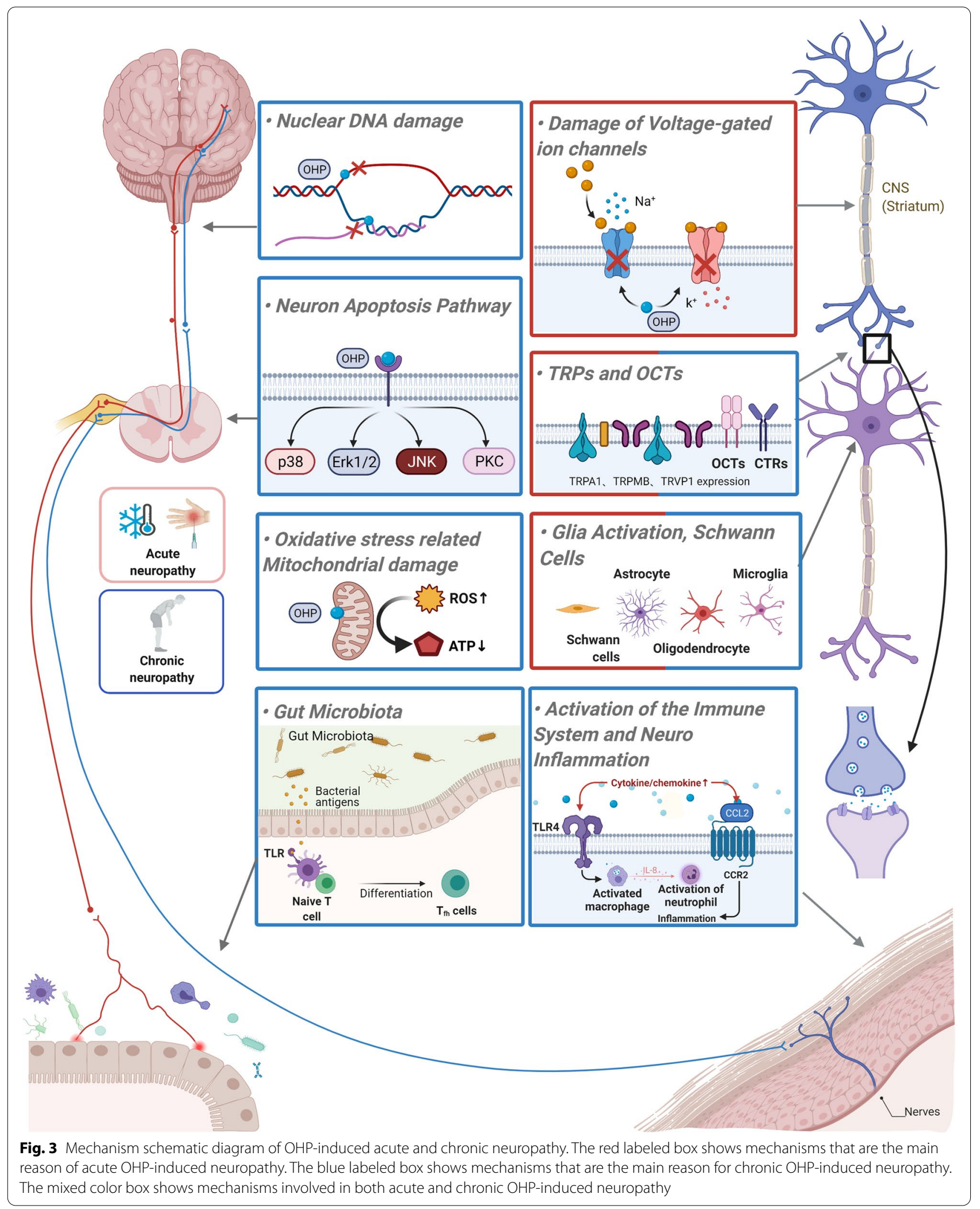


Table 5 A summary of the possible mechanisms involved in the development of oxaliplatin-induced neuropathic pain

\begin{tabular}{|c|c|c|}
\hline Targets & Mechanisms & References \\
\hline \multirow[t]{2}{*}{$\mathrm{Na}^{+}$channel } & $\begin{array}{l}\text { Prolonged open state and slow inactivation of the } \mathrm{Na}^{+} \text {channels in } \\
\text { acute OIPN }\end{array}$ & {$[12,55-57]$} \\
\hline & Induced abnormalities of $\mathrm{Na}^{+}$currents in chronic OIPN & {$[58]$} \\
\hline \multirow[t]{3}{*}{$\mathrm{K}^{+}$channel } & Increasing the expression of the pro-excitatory $\mathrm{K}+$ channels & {$[59]$} \\
\hline & $\begin{array}{l}\text { Decreased expression of two-pore domain } \mathrm{K}^{+} \text {channels (TREK-1 } \\
\text { and TRAAK) in DRG }\end{array}$ & {$[60,61]$} \\
\hline & CAG repeat polymorphisms in the KCNN3 gene & {$[62]$} \\
\hline \multirow[t]{3}{*}{$\mathrm{Ca}^{2+}$ channel } & Oxalate as a calcium chelator contributes to the acute form of OIPN & {$[63]$} \\
\hline & $\begin{array}{l}\text { Increased expression of the Cava } \delta-1 \text { subunit mRNA and protein } \\
\text { in cold hypersensitivity }\end{array}$ & {$[64,65]$} \\
\hline & Reduction in P/Q-, T-, and L-type $\mathrm{Ca}_{\mathrm{v}}$ channel currents & {$[66]$} \\
\hline \multirow[t]{3}{*}{ Transient receptor potential channels } & $\begin{array}{l}\text { Up-regulation of the mRNA of the TRPV1, TRPA1, and TRPM8 in } \\
\text { cultured DRG neurons }\end{array}$ & {$[67]$} \\
\hline & $\begin{array}{l}\text { OHP-induced cold allodynia in vivo was found to enhance the } \\
\text { sensitivity and expression of TRPM } 8 \text { and TRPA1 }\end{array}$ & {$[68,69]$} \\
\hline & Oxaliplatin and oxalate cause TRPA1 sensitization to ROS & {$[70,71]$} \\
\hline \multirow[t]{2}{*}{ Transporters } & CTRs (CTR1) and OCTs (OCT2) mediate the uptake of OHP & {$[48,72]$} \\
\hline & ATP7A and ATP7B facilitate the cellular efflux of OHP & [73] \\
\hline Nuclear DNA damage & Formation of platinum DNA adducts & {$[57,74]$} \\
\hline \multirow[t]{5}{*}{ Oxidative stress-related mitochondrial damage } & $\begin{array}{l}\text { Neuronal mitochondrial dysfunction resulting in nitro-oxidative } \\
\text { stress }\end{array}$ & {$[2,75]$} \\
\hline & Bind to mitochondrial DNA and formation of adducts & [76] \\
\hline & $\begin{array}{l}\text { Oxidative stress could gate TRPA1, produce nociceptive responses } \\
\text { and neurogenic inflammation, and cause demyelination and } \\
\text { disruption of the cytoskeleton of peripheral nerves }\end{array}$ & {$[77,78]$} \\
\hline & $\begin{array}{l}\text { Lead to electron transport chain disruption and cellular energy } \\
\text { failure in DRG neurons }\end{array}$ & {$[79]$} \\
\hline & Nrf2 may play a critical role in ameliorating OIPN & {$[67,80]$} \\
\hline \multirow[t]{4}{*}{ Activation of the immune system and neuroinflammation } & $\begin{array}{l}\text { Increased levels of CCL2 and CCR2 accompanied by mechanical } \\
\text { hypersensitivity }\end{array}$ & {$[81]$} \\
\hline & IL-8 signaling pathway is involved in neuroinflammation & {$[82]$} \\
\hline & Gut microbiota -TLR4 activation on macrophages & {$[83]$} \\
\hline & Increased circulating $\mathrm{CD}^{+}{ }^{+}$and $\mathrm{CD} 8^{+}{ }^{+}$-cells & {$[84]$} \\
\hline \multirow[t]{2}{*}{ Glia activation } & $\begin{array}{l}\text { Increase of neuro-immune activation resulting in converted neuro- } \\
\text { transmission }\end{array}$ & [85-89] \\
\hline & $\begin{array}{l}\text { Transient activation of microglia and astrocytes in the spinal cord } \\
\text { and supraspinal areas }\end{array}$ & \\
\hline Schwann cells & Mitochondrial dysfunction in Schwann cells & {$[90]$} \\
\hline \multirow[t]{2}{*}{ Central nervous system structures and neurotransmitters } & $\begin{array}{l}\text { Altered levels of neurotransmitters, such as catecholamines, hista- } \\
\text { mine, serotonin, glutamate, and GABA }\end{array}$ & [91-93] \\
\hline & GLT-1 and GLAST and EAAT1 dysfunction & {$[94,95]$} \\
\hline \multirow[t]{3}{*}{ Caspases and MAP-kinases, Protein kinase C, and PI3K/Akt2 pathway } & $\begin{array}{l}\text { Early activation of the MAP-kinase proteins } \mathrm{p} 38 \text { and ERK } 1 / 2 \text {, which } \\
\text { promotes apoptosis-mediated cell death in rat DRG neurons }\end{array}$ & {$[96]$} \\
\hline & $\begin{array}{l}\text { Up-regulates the gamma isoforms of PKC and increases in the } \\
\text { phosphorylation of gamma/epsilon PKC isoforms }\end{array}$ & {$[97]$} \\
\hline & PI3K/Akt2 activation & {$[98]$} \\
\hline MicroRNA regulation & $\begin{array}{l}\text { MiR-15b down-regulation of BACE1 contributes to chronic neuro- } \\
\text { pathic pain }\end{array}$ & [99] \\
\hline
\end{tabular}


Table 5 (continued)

\begin{tabular}{|c|c|c|}
\hline Targets & Mechanisms & References \\
\hline \multirow[t]{4}{*}{ Gut microbiota } & $\begin{array}{l}\text { Different microbe-associated molecular patterns (MAMPs) bind to } \\
\text { their TLRs }\end{array}$ & {$[100]$} \\
\hline & $\begin{array}{l}\text { LPS can directly mediate the gating of TRPA } 1 \text { and increase calcium } \\
\text { influx }\end{array}$ & {$[101,102]$} \\
\hline & $\begin{array}{l}\text { Chemotherapy decreased numbers of "beneficial" bacteria, such } \\
\text { as Lactobacillus and Bifidobacteria, while Lactobacillus acidophilus } \\
\text { exerts anti-tumor effects while preventing the incidence of the } \\
\text { toxic adverse events }\end{array}$ & {$[103,104]$} \\
\hline & $\begin{array}{l}\text { Microbiome-gut-brain and the neuroimmune-endocrine axis } \\
\text { involved in the manifestations of OIPN }\end{array}$ & {$[103]$} \\
\hline
\end{tabular}

ATP7A ATPase Copper Transporting Alpha, BACE1 Beta-secretase 1, Cava2 $\delta$ - 1 Calcium voltage-gated calcium channel alpha2/delta subunit, CCL2 C-C motif chemokine 2, CCR2 C-C-Motif Receptor 2, CD4 + Cluster of Differentiation 4 receptors, CD8 + Cluster of Differentiation 8 receptors, CTRs Copper transporters, DNA Deoxyribonucleic acid, DRG Dorsal root ganglion, DRG Dorsal root ganglion, ERK1/2 Extracellular regulated kinase 1/2, GABA $\gamma$-aminobutyric acid, GLAST EAAT1, glutamate aspartate transporter, GLT-1 Glutamate transporter 1, IL-8 Interleukin-8, KCNN3 Potassium channel SK3, LPS Lipopolysaccharides, MAMPs Microbe-associated molecular patterns, OCTS Organic cation transporters, OIPN Oxaliplatin induced peripheral neuropathy, PI3K/Akt2 Phosphatidylinositol 3 kinase/ protein kinase B, PKC Protein kinase C, ROS Reactive oxygen species, TLR Toll-like receptors, TLR4 Toll-like receptors 4, TRAAKTWIK-related arachidonic acid-stimulated K+ channel, TREK-1 TWIK-Related K+ channel 1, TRPA1 Transient receptor potential A1, TRPM8 Transient receptor potential cation channel subfamily M member 8 , TRPV1 Transient receptor potential vanilloid 1

$\mathrm{K}^{+}$-channels $\left(\mathrm{K}_{\mathrm{v}} 7\right)$ reduced the OHP-induced hyperexcitability [108].

\section{$\mathrm{Ca}^{2+}$ channel}

Calcium chelator-oxalate contributes to the development of an acute form of OIPN. The administration of $\mathrm{Ca}^{2+}$ gluconate and $\mathrm{Mg}^{2+}$ sulfate was shown to reduce subsequent OHP-induced neuropathy [63]. The crucial role of the calcium voltage-gated calcium channel alpha2/ delta $\left(\mathrm{Ca}_{\mathrm{v}} \mathrm{\alpha}_{2} \delta-1\right)$ subunit in the development of OHPinduced acute and delayed cold hypersensitivity has also been shown in rodents $[64,65] . \mathrm{Ca}_{\mathrm{v}}$ channel currents are reduced by OHP in a concentration-dependent manner. Acute OHP treatment leads to a reduction in the $\mathrm{L}-, \mathrm{T}-$, and $\mathrm{P} / \mathrm{Q}$-type $\mathrm{Ca}_{\mathrm{v}}$ channel currents. In contrast, prolonged OHP exposure to DRG neurons significantly increases $\mathrm{T}$ - and $\mathrm{L}$-type $\mathrm{Ca}_{\mathrm{v}}$ channel currents. Increased $\mathrm{T}$ - and L-type $\mathrm{Ca}_{\mathrm{v}}$ channel protein levels in DRG neurons have also been noted after OHP exposure [66]. Furthermore, treatment with $\mathrm{Ca}^{2+}$ channel blockers to limit the $\mathrm{Ca}^{2+}$ influx is employed clinically [63].

\section{Transient receptor potential channels}

OHP-induced cold allodynia was found to enhance the sensitivity and expression of transient receptor potential cation channel subfamily $M$ member 8 (TRPM8) and transient receptor potential vanilloid1 (TRPA1) in vivo [67-69]. OHP and oxalate have been shown to cause reactive oxygen species (ROS)-related TRPA1 sensitization by inhibiting prolyl hydroxylases. OHP-induced TRPA1 sensitization to ROS is believed to be caused by enzyme inhibition, enabling ROS signals to convert into cold sensitivity by TRPA1 [70, 71].
Moreover, OHP induces the hydrogen peroxide rapid generation and evokes cysteine oxidation-dependent human TRPA1 (hTRPA1) activation mediated by ROS, and glutathione can prevent the observed calcium influx $[66,70,109]$. It has been demonstrated that TRPM8 blocking by the administration of capsazepine inhibits OHP-induced cold allodynia in mice [68]. However, the use of the selective TRPV1 blocker suggests that TRPV1's antagonistic and partial agonistic actions do not affect OHP-induced cold allodynia [110].

\section{Transporters}

Organic cation transporters (OCTs) and copper transporters (CTRs) can mediate the uptake of OHP through their influence on the OHP influx and efflux of DRG neurons $[48,72]$. The OCT2 protein was detected in human and mouse DRGs [111]. Single-dose OHP increased the sensitivity to cold and mechanical stimulation significantly in WT mice, compared with OCT2 knockout mice, and it was required at the acute OHPinduced peripheral neuropathy onset. Over-expressions of copper transport 1 (CTR1) and OCT2 in DRG neurons have resulted in OHP accumulation, leading to aggravation or development of the neuropathy [48]. ATPase Copper Transporting Alpha (ATP7A) can facilitate the OHP cellular efflux, reducing the possibility of OHP-DNA adducts forming. Thus, it was hypothesized that ATP7A-expressing DRG neurons are less sensitive to OHP-induced neuropathy. In contrast, high levels of CTR1 expressing DRG neurons would be expected to absorb more OHP, which could lead to toxic neuropathy effects [112]. 


\section{Nuclear DNA damage}

Platinum is accumulated easily in the DRG neurons due to the abundant fenestrated capillary network and the lack of the blood-nerve barrier in the DRG $[74,113]$. The accumulation of platinum-DNA adducts formation is considered the key factor in OIPN development [57, 74]. A correlation between platinum-DNA adduct levels and the degree of neuropathy has been identified [96]. Cisplatin-produced adducts were approximately three times higher than those generated by equimolar OHP doses, which in accordance with cisplatin caused significantly greater neuronal cell deaths than OHP in vitro [96]. The results may explain the symptom that OHP-induced neuropathy showed improved outcomes compared with other platinums.

\section{Oxidative stress-related mitochondrial damage}

Neuronal mitochondrial dysfunction resulting in nitrooxidative stress [114] plays a critical role in OHP-induced neuropathy $[2,75]$. Due to the lack of DNA repair systems, OHP-DNA adducts cannot be repaired within the mitochondria. Evidence has shown the relationship between oxidative stress and OHP-induced neuropathy [76]. Furthermore, OHP causes damage to both neuronal and nonneuronal mitochondria, leading to oxidative stress burden mediated by the redox-sensitive TRPA1 channels, which correlate with OHP-induced cold and mechanical hypersensitivity [71, 115-117]. The ROS generated by OHP treatment has been shown to modulate sodium channel activity, influencing the sensitivity of nociceptors [118]. Alterations in the mitochondrial structure and function in OHP-exposed rat neuronal cells have been shown in vitro $[119,120]$. Moreover, OHP can produce toxic effects on axonal mitochondria, which lead to electron transport chain dysfunction and failure of cellular energy in the DRG neurons [79]. The antioxidant Acetyl-1-Carnitine treatment inhibits the OHP-triggered hyperalgesia development by preventing the respiratory chain damage, further leading to the maintenance of mitochondrial integrity [79]. However, the effects of antioxidants (vitamin $\mathrm{C}$, etc.) in OIPN require further clinic tests and verifications.

\section{Activation of the immune system and neuroinflammation}

The mRNA levels of proinflammatory cytokines and chemokines increase accompanied by OHP administration, and a strong correlation of this effect with the mechanical hypersensitivity development has been shown [81]. The IL-8 signaling pathway is involved in neuroinflammation, resulting in progressive neural sensitization in OIPN model [82]. Increased levels of C-C motif chemokine 2 (CCL2) and C-C-Motif Receptor 2 (CCR2) in the DRG neurons have also been observed to be accompanied by a mechanical hypersensitivity in OHP-treated rats [121]. Toll-like receptors (TLR) are widely expressed on immune cells, enterocytes, sensory neurons, and glial cells. OHP-induced mechanical hyperalgesia and neuroinflammation are mediated by gut microbiota-related Toll-like receptors 4 (TLR4) activation on macrophages $[83,122,123]$. T-cells (Th17 and Th1) are also involved in the possible sources of inflammatory factors and potential drivers of neuropathic pain. In OHP-treated male mice, significant mechanical allodynia was accompanied by an increased circulating cluster of differentiation 4 receptors $\left(\mathrm{CD} 4^{+}\right)$and cluster of differentiation 8 receptors $\left(\mathrm{CD}^{+}\right)$T-cells [84]. Since chemotherapy-associated inflammation is regarded as a key mechanism of neuroinflammation involved in OIPN [84], the complex interaction between neurons, immune system, and cancer cells must be considered.

\section{Glia activation and Schwann cells}

Abnormal communication between the neurons and the glia plays a significant role in OHP-induced neuropathic pain [124]. This dysfunction can arise from the increasing neuro-immune activations, resulting in converted neurotransmissions within the dorsal horn of the spinal cord. This has been substantiated by the evidence that pharmacological treatments (i.e., minocycline [85] and fluorocitrate [86]) can relieve neuropathic pain through the prevention of glial activation. It has been shown that following the intraperitoneal administration of OHP, transient activation of the microglia and the astrocytes in supraspinal areas and the spinal cord is involved in the modulation of pain accompanied by a decrease in the thermal and mechanical pain thresholds [87]. During neuropathy, the numbers of ionized calcium binding adapter molecule 1 (Iba1) (microglia) and glial fibrillary acidic protein (GFAP) (astrocyte) immune-positive cells showed an increase in the dorsal horn of the spinal cord, concomitantly with a decrease of pain threshold and a glia density increase in various supraspinal sites [88]. The uptake and metabolism process of OHP in glia cells and neurons should be considered. Furthermore, OHP induces intra-epidermal nerve fibers loss and moderate axonal degeneration in patients [125]. The OHP-induced cytotoxicity in primary Schwann cells and the myelin basic protein expression decreasing indicated that the platinum derivatives also induced Schwann cells mitochondrial dysfunction in vitro [90].

\section{Central nervous system structures and neurotransmitters}

Altered levels of several neurotransmitters are associated with OIPN [91-93]. In OHP-treated rats, the blockade of proinflammatory cytokine receptors results in $\gamma$-aminobutyric acid (GABA) function recovery and the 
cold and mechanical hypersensitivity relief [126]. These transport proteins have been observed in OHP-treated neuropathic rats [94]. Single-dose and repeated doses of ceftriaxone, a beta-lactam antibiotic upregulating glutamate transporter 1 (GLT-1) expression, increases glutamate reuptake in the central nervous system (CNS) $[127,128]$. It was tested for effectiveness in relieving early-phase and late-phase mechanical and thermal hyperalgesia in OHP-treated mice. The results confirmed previous findings, which suggested that the GLT-1 biological functions are associated to a greater extent with the regulation of the mechanical- than the cold-nociceptive threshold [129]. The effect of tiagabine, a highly selective inhibitor of GABA transporter subtype 1 (GAT1 ), on OHP-induced neuropathic pain was assessed in mice [130]. However, the central effects of chemotherapy neurotoxicity are mainly related to cognitive impairment ("chemofog" or "chemobrain") of the central nervous system in OIPN [88, 131, 132]; it is important to investigate the central nervous system with magnetic resonance imaging at the functional level or to modulate its activity using transcranial stimulation to develop new therapeutic strategies [133].

\section{Neuron apoptosis pathway}

Prolonged OHP exposure induces the phosphoprotein 38 (p38) and extracellular regulated kinase $1 / 2$ (ERK1/2) early activation, which promotes the apoptosis of DRG neurons, and the down-regulation of protective c-JunNH2-terminal kinase /stress activated protein kinase (JNK/Sapk), which increase OHP neurotoxic effects in vitro $[96,134]$. This was further evidenced by using a caspase inhibitor (z-VAD-fmk), which indicated the involvement of caspases in OHP-induced neuropathy. Furthermore, restoring the MAP-kinases' physiological functions, through the treatment of the DRG neurons with retinoic acid or NGF, is neuroprotective against OHP-induced neuropathy in vitro [135]. The gamma isoforms of protein kinase $\mathrm{C}$ (PKC) and the phosphorylation of gamma/epsilon PKC isoforms are increased in the brain in an OIPN model, and PKC inhibitors (Calphostin $\mathrm{C}$, hypericin) attenuate OHP-induced mechanical hyperalgesia [97]. A cyclooxygenase-2 (COX-2) inhibitor (celecoxib) inhibits the phosphatidylinositol 3 kinase/ protein kinase B (PI3K/Akt2) pathway and can also attenuate OHP-induced neuropathic pain [98].

\section{Gut microbiota}

Recent studies have demonstrated that gut microbiota is involved in pain modulation [136], and the different types of peripheral neuropathies induced by $\mathrm{OHP}$ in both the c mice and germ-free (GF) mice have indicated that the gut microbiota is critical to the induction and pathogenesis of OIPN [83]. Mechanically different microbe-associated molecular patterns (MAMPs) binding to the TLRs activate resident immune cells with the release of numerous chemokines and cytokines by the immune cells, which subsequently alters the transmission and transduction of nociceptive sensory neurons [100]. Moreover, lipopolysaccharides (LPS) can mediate the gating of TRPA 1 directly and increase calcium influx $[101,102]$. The gut microbiota serves as a connection between the microbiome-gut-brain and the neuroimmune-endocrine axes, forming a complex network that can influence main components involved in the symptoms of OIPN directly or indirectly [103]. Patients always receive antibiotic prophylaxis to prevent infection before chemotherapy onset in clinical settings. However, the necessity of this antibiotic prevention and the type of patient suitable for this treatment are not clear. The antibiotics may imbalance the gut microbiota and aggravate the OIPN. The instructions for antibiotic prophylaxis need to be evaluated in order to prevent the unexpected side effects of chemotherapy. This also highlights the need for targeted therapeutically specific microflora for successful treatment regimens to be explored.

\section{Chemotherapy-induced peripheral neuropathy prevention and treatment: therapy candidates for OIPN}

The National Cancer Institute's Symptom Management and Health-Related Quality of Life Steering Committee has announced that CIPN is a priority area in translational research in cancer care [137]. However, based on the background described previously, this is not yet completely feasible. Current pharmacological approaches do not have a sound rationale, and there is a strong medical demand for novel therapeutic regimens. Moreover, the latest literature data indicate clearly that although numerous preventive therapies have been tested for their potential utility to alleviate CIPN, it is currently still not preventable [138-140], and many strategies that were tested were found to be ineffective. Duloxetine is the only drug moderately recommended by the American Society of Clinical Oncology (ASCO) for the prevention of OIPN [1, 2]. Other drugs such as venlafaxine, pregabalin, and carbamazepine have also been assessed, but their utility for the prevention of oxaliplatin-induced CIPN is still controversial (Table 6). These guidelines show that due to the lack of high-quality and strong evidence for the action 
Table 6 A summary of ASCO recommendations for preventative and treatment therapies for CIPN

\begin{tabular}{|c|c|c|}
\hline Strength of recommendation & Preventative therapies & Treatment therapies \\
\hline Strong recommendation against & Acetyl-L-carnitine & None \\
\hline Moderate recommendation against & $\begin{array}{l}\text { Acetylcysteine, Amifostine, Amitriptyline, Calcium } \\
\text { and magnesium, Cannabinoids, Calmangafodipir, } \\
\text { Carbamazepine/oxcarbazepine, L-carnosine, DDTC, } \\
\text { Gabapentin/pregabalin, Glutamate/glutamine, GSH, } \\
\text { GJG-Kampo medicine, Metformin, Minocycline, } \\
\text { Nimodipine, Omega 3, Org 2766, Retinoic acid, } \\
\text { rhuLIF, Venlafaxine, Vitamin B, Vitamin E }\end{array}$ & None \\
\hline Inconclusive date: No recommendation & $\begin{array}{l}\text { Acupuncture, Compression therapy, Cryotherapy, } \\
\text { Exercise, GM1, }\end{array}$ & $\begin{array}{l}\text { Acupuncture, Exercise, Gabapentin/pregabalin, BAK, } \\
\text { Oral cannabinoids, Tricyclic antidepressants, Scrambler } \\
\text { therapy }\end{array}$ \\
\hline Moderate recommendation for & None & Duloxetine \\
\hline Strong recommendation for & None & None \\
\hline
\end{tabular}

BAK Topical amitriptyline, ketamine, 6 baclofen, CIPN Chemotherapy-induced peripheral neuropathy, DDTC Diethyldithiocarbamate, GJG Goshajinkigan, GM1 Monosialotetrahexosylganglioside, GSH Glutathione, rhuLIF Recombinant human leukemia inhibitory factor

of the agents tested, there are no clear algorithms for CIPN prevention or treatment (Table 7).

\section{Ion channel-targeted therapies Riluzole}

Riluzole prevents the excessive glutamate accumulation in OIPN, and benefits sensorimotor and painful disorders of the peripheral nervous system [94]. It has been shown to alleviate OHP-induced peripheral nerve dysfunctional and morphological alterations [61]. It also has been hypothesized that riluzole may exert its neuroprotective action through interaction with the potassium channels TREK and TRAAK [175]. Recently, riluzole has initiated a phase II, placebo-controlled, randomized, double-blind, parallel, multicenter, prevention trial with adult stage II/III colorectal cancer patients treated with a simplified FOLFOX4 regimen in the adjuvant setting (NCT03722680).

\section{Lidocaine}

Lidocaine is a sodium channel antagonist [142], and it was first assessed to revealed a significant alleviation of the cold and mechanical allodynia induced by OHP in rodent models [56, 176]. In a small study, the IV administration of lidocaine had a direct analgesic effect in CIPN and a moderate long-term effect through modulation of the cold and pinprick perception [143]. A pilot study was conducted to determine the tolerative and effective of IV lidocaine treatment to reduce the severity of OHPinduced cold hypersensitivity in modified FOLFOX6 (mFOLFOX6) chemotherapy patients. However, there remains a lack of convincing evidence supporting its efficacy [177].

\section{Pregabalin}

Pregabalin displays an anti-nociceptive effect by voltagegated calcium channels blockade and the down-regulation of excitatory neurotransmitters [144]. A powerful analgesic effect of pregabalin on OIPN has been reported [178]. In three clinical cases, pregabalin successfully demonstrated a therapeutic effect; however, it was accompanied by similar side effects to those of gabapentin [179]. Oral administration of pregabalin reduced grades 1-2 severity of sensory neuropathy induced by OHP. However, in a Phase III trial (143 patients), the preadministration of oral pregabalin during OHP infusion did not improve the chronic pain, life quality, or mood of the cancer patients [180]. Thus, the efficacy of pregabalin against CIPN requires further confirmation. In a current Phase III study, pregabalin was administrated exclusively for 3 days before and after the OHP infusion; it was able to prevent the occurrence of pain secondary to both the acute and chronic OIPN (NCT01450163).

\section{Calcium and magnesium infusions}

Calcium and magnesium $(\mathrm{Ca} / \mathrm{Mg})$ infusions are promising strategies for preventing OIPN. The intravenous delivery of calcium and magnesium facilitates the blocking of sodium channels [145]. In a large phase III study (720 advanced colorectal cancer patients/551 patients received $\mathrm{Ca} / \mathrm{Mg}$ infusions before chemotherapy), $\mathrm{Ca} /$ $\mathrm{Mg}$ infusion decreased all grade incidence of the sensory neurotoxicity induced by OHP $[146,147]$. However, in a double-blind phase III study (involving 353 colon cancer patients), intravenous $\mathrm{Ca} / \mathrm{Mg}$ showed no benefit regarding the incidence of OHP-induced acute neurotoxicity symptoms when compared with a placebo [148]. A further two cases showed that $\mathrm{Ca} / \mathrm{Mg}$ infusions altered 
Yang et al. J Exp Chin Cancer Res <wide> <wide>(2021) 40:331

Page 12 of 25

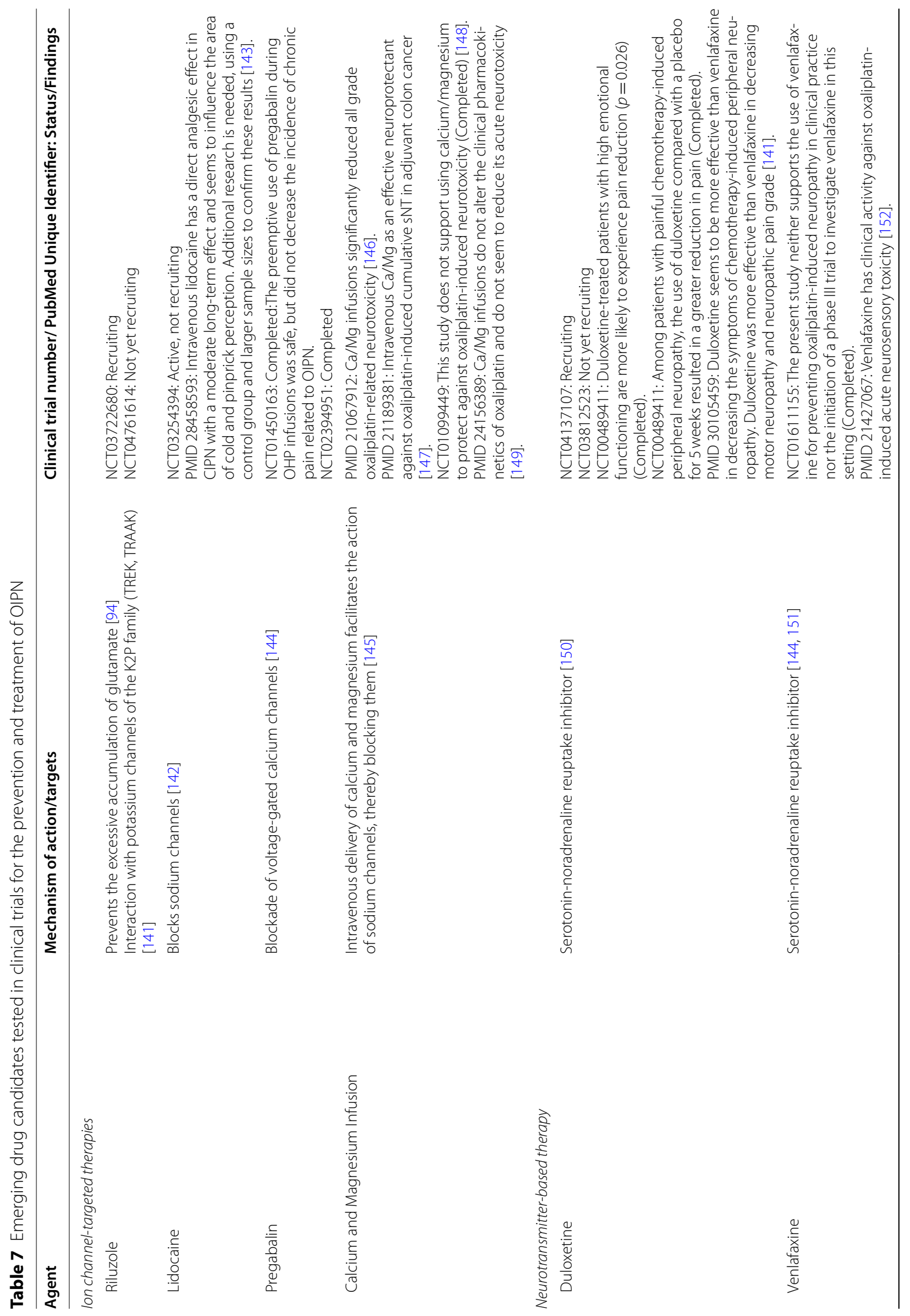


Yang et al. J Exp Chin Cancer Res <wide> <wide> (2021) 40:331

Page 13 of 25






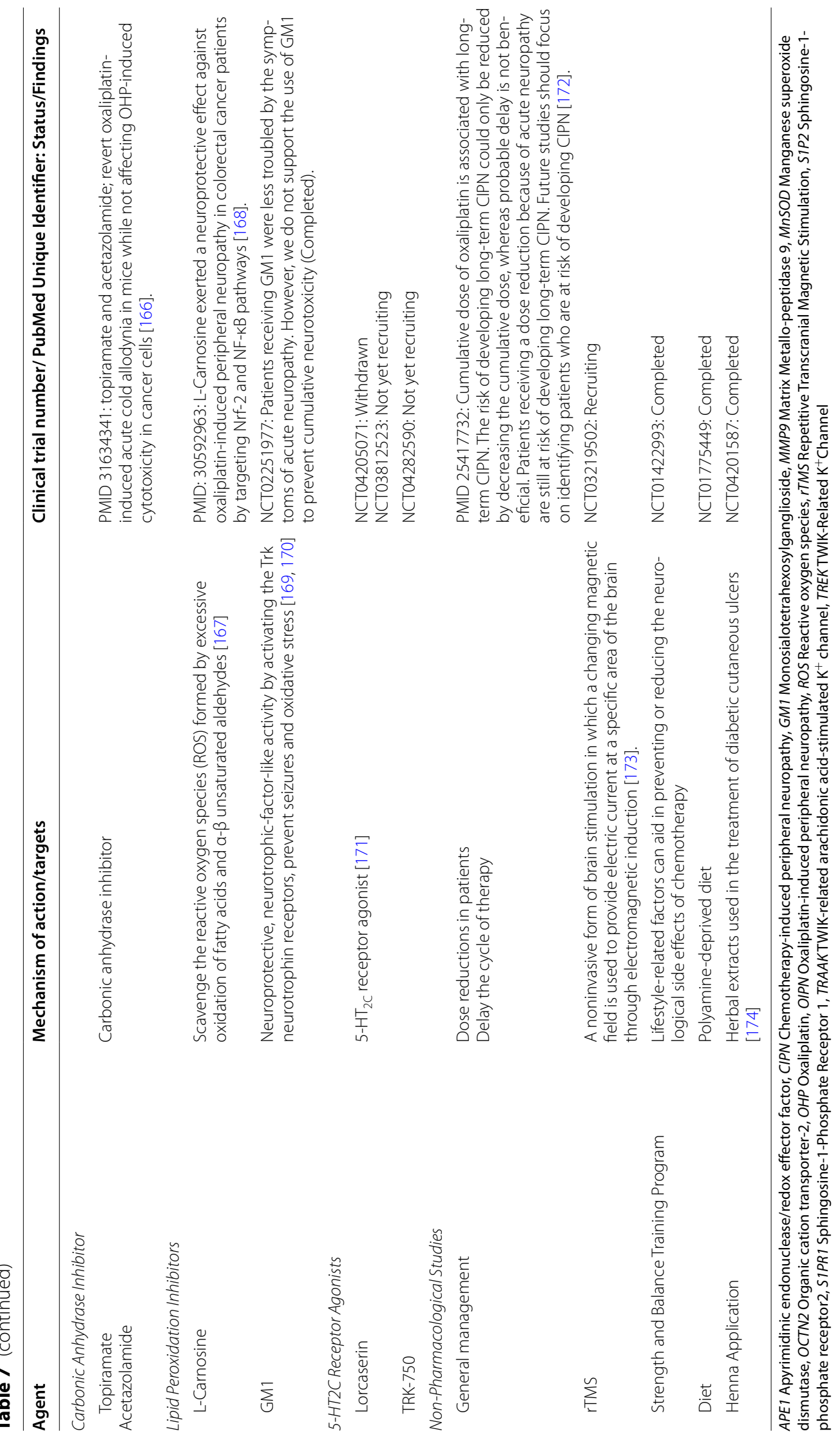


neither the acute nor the chronic neurotoxicity induced by OHP [149]. Thus, the utility of $\mathrm{Ca} / \mathrm{Mg}$ infusions should be examined further.

\section{Neurotransmitter-based therapies Duloxetine}

The antidepressant drug duloxetine, which acts as a serotonin-noradrenaline reuptake inhibitor (SNRI), can effectively alleviate symptoms of OIPN without reducing the antitumor activity of OHP based on the preclinical and clinical studies $[137,150,181]$. While ASCO recommends the use of duloxetine as a potential treatment for CIPN, sufficient evidence is still lacking. Thus, identifying predictors of duloxetine response and optimizing the treatment schedule is a priority as it is not completely effective and works for everyone. Furthermore, the patients with OIPN are more likely to benefit from duloxetine than patients with a paclitaxel-induced neuropathy based on an exploratory responder analysis [182], which suggests that action of duloxetine's pharmacodynamic effect may be tightly associated with specific molecular mechanisms underlying OIPN [183, 184]. In addition, the administration of duloxetine was reported to have fewer adverse effects compared with venlafaxine [184]. Moreover, duloxetine had a better effect on reducing neuropathic pain severity and grade of motor neuropathy than venlafaxine [141]. Recently, duloxetine has initiated a phase II/III study investigating the best dose of duloxetine and how well it worked in preventing pain symptoms caused by OHP in stage II-III colorectal cancer patients (NCT04137107).

\section{Venlafaxine}

Venlafaxine, a more selective SNRI, has been used to prevent CIPN [144]. In a randomized phase III trial, venlafaxine displayed clinical activity against acute neurosensory toxicity induced by OHP; however, its side effects should not be ignored, including asthenia (39.2\%) and nausea (43.1\%) [152]. A greater analgesia benefit of SNRIs was observed in platinum-treated than in taxanes-treated patients; however, clinical data showed that duloxetine may improve CIPN symptoms more than venlafaxine [185]. Moreover, a direct comparison between duloxetine and venlafaxine is necessary. Unfortunately, a randomized pilot study on 50 patients failed to demonstrate the efficacy of venlafaxine in CIPN patients [151].

\section{Antioxidants}

\section{Amifostine}

Amifostine was first used in the prevention of OIPN in a randomized trial. Neuropathy was reported on days when OIPN patients experienced sensitive peripheral neuropathy or cold-associated paresthesia. Amifostine administration showed significantly less neuropathy in the treatment group, whereas, toxicity of amifostine was not addressed. The intravenous administration of amifostine can cause significant adverse effects, including nausea, hypotension, and vomiting. The subcutaneous route of amifostine can significantly improve its tolerance $[153,154]$.

\section{Calmangafodipir}

Targeting manganese superoxide dismutase (MnSOD) has emerged as a promising strategy to prevent OIPN symptoms [186, 187]. A derivative of mangafodipir, calmangafodipir (Ca4Mn(DPDP)5, PledOx $\left.{ }^{\circledR}\right)$, which is a cytoprotectant agent and a magnetic resonance imaging contrast agent $[155,156]$, is a mitochondrial MnSOD mimetic that can reduce ROS tissue levels. However, these compounds have been confirmed to have significant neuroprotective and preventive activity in OIPN preclinical and clinical data $[186,187]$. Furthermore, the neuroprotection effect of calmangafodipir may also be possible with other chemotherapeutic agents [137, 188]. In a phase II study in colorectal cancer patients treated with OHP, calmangafodipir reduced cold allodynia and other sensory symptoms without reducing its antineoplastic efficacy [188]. Two international trials (POLAR A and POLAR M) have been initiated to evaluate the efficacy of calmangafodipir in prevention of OHP-induced neuropathy in colorectal cancer patients. Results are expected in the years 2020/2021 (POLAR A) or 20212023 (POLAR M) [137].

\section{Anti-inflammatory therapies Minocycline}

Minocycline, a microglia inhibitor and a matrix metallopeptidase 9 (MMP9) blocker, inhibits the release of proinflammatory cytokines and alleviates the development and symptoms of OIPN $[157,158]$. It has been reported that minocycline treatment effectively prevented the mechanical sensitivities and the loss of IENFs in OIPN models [189]. In 2017, a pilot study reported that minocycline did not reduce the CIPN overall sensory neuropathy. However, compared with the placebo, it decreased the average pain score and fatigue in CIPN patients [159]. Therefore, minocycline may be a promising candidate for the prevention and treatment of CIPN. Large clinical trials and preclinical studies are needed to further evaluate its effect on CIPN.

\section{Targeting chemotherapeutic drug uptake transporters}

Two tyrosine kinase inhibitors, nilotinib (an organic anion transporting polypeptide 1B2 (OATP1B2) inhibitor) and dasatinib (an OCTN2 inhibitor), may provide a potential neuroprotective strategy for OIPN, without 
impacting negatively on their systemic clearances or antitumor efficacies through in vitro and in vivo studies. In a phase II study, nilotinib and dasatinib are currently being studied in an ongoing phase IB trial as repurposed drugs [137].

\section{Targeting apurinic/apyrimidinic endonuclease function} Impaired DNA repair within the sensory nervous system is associated with CIPN formation. The apyrimidinic endonuclease/redox effector factor (APE1) is an important enzyme for DNA-damaged base removal, and decreased APE1 levels in sensory neurons increase neurotoxicity in OIPN models, targeting APE1 by the small molecules APX3330 and APX2009. This has been shown to provide neuroprotection against OIPN. APX2009 also shown a strong effect of tumor cell-killing. These data suggest that such compounds may be effective in preventing or reversing platinum-induced neuropathy without affecting the anticancer ability of the platinum-based chemotherapies [190]. Currently, clinical trials are being conducted with APX3330, regarding CIPN prevention as an antineoplastic agent.

\section{Targeting the inhibition of neuronal apoptosis and astrocyte activation}

OHP induces the dysregulating sphingolipid metabolism, and leads to increased formation of sphingosine1-phosphate (S1P) in the development of CIPN [162]. Sphingosine kinase inhibitors reversed CIPN symptoms by blocking the formation of S1P [191]. Fingolimod (FTY720) acts as a nonselective agonist of SIP receptors. Daily FTY720 injections have been shown to inhibit the development of hyperalgesia and mechanical allodynia induced by OHP [162]. Similar effects were also found with other S1P1 antagonists. S1P1 antagonists may act synergistically without reducing the anticancer activity of chemotherapeutic agents [192], making fingolimod and its analogs promising agents for the prevention of OIPN [193]. Moreover, fingolimod-induced transient cardiovascular adverse effects must be considered for CIPN prevention and treatment [137].

\section{Sigma-1 receptor antagonism}

The sigma-1 receptors may constitute a novel drug target candidates for OIPN [163], and MR309, a selective sigma-1 receptor antagonist, has attenuated symptoms of OIPN [194]. A phase II clinical trial with MR309 has been completed in patients with colorectal cancer receiving OHP therapy [194]. Compared with the placebo, MR309 significantly reduced the threshold of cold pain and lowered the proportion of patients with severe chronic neuropathy. Continuous dosing during the full chemotherapy period and different dose regimens of MR309 administration require testing in further studies [194].

\section{Angiotensin II type 2 receptor antagonism}

EMA401 (olodanrigan) is an antagonist of angiotensin II type 2 (AT2) receptor. Oral EMA401was tested for effectiveness in CIPN patients in clinical trials. Although EMA401 showed anti-neuropathic properties in painful diabetic neuropathy and postherpetic neuralgia patient populations, these trials were terminated or withdrawn due to the observed side effects of EMA401 [93, 94, 126, 127]. An open-label biomarker study of EMA401 was conducted in a phase II clinical trial of OIPN patients to prove the conceptual use of EMA401 in OIPN. However, because the statistical analyses were not specified as only one arm was reported, the trial results were inconclusive and difficult to interpret.

\section{Carbonic anhydrase inhibitor}

Therapeutically relevant concentrations of OHP have demonstrated a decrease in the DRG pH value in mice by forming adducts with hemoglobin in in vivo and in vitro experiments. Moreover, the FDA-approved drugs, i.e., acetazolamide and topiramate, alleviate OHP-induced acute cold allodynia in mice without affecting OHPinduced tumor-killing effect in vivo. The results indicate a novel strategy for future OIPN clinical treatment [195].

\section{Lipid peroxidation inhibitors \\ L-carnosine}

L-carnosine, in combination with alpha-lipoic acid, showed a significant reduction in neuropathic pain and good tolerability in an animal model of OIPN. The mechanism of L-carnosine revealed that its calcium-binding carnosine moiety exerts a persistent activity through a TRPA1 synergically stabilized binding through covalent binding to the lipoic acid residue of the channel [196]. The prophylactic effect of exogenous L-carnosine in the prevention of oxidative stress was evaluated in an open-label prevention study, in which the chemotherapy patients received $500 \mathrm{mg}$ per day L-carnosine orally, and the neuropathy grading score of the National Cancer Institute-Common Toxicity Criteria for Adverse Events was applied to assesses the peripheral neuropathy [197].

\section{GM1}

Monosialotetrahexosylganglioside (GM1) is important in nerve development, differentiation, and repair after injuries [169]. It also acts to prevent oxidative stress and seizures [170]. GM1 was initially applied to treat Parkinson's disease and vasculogenic or traumatic central nervous impairments treatment [169]. GM1 attenuated the symptoms of acute neuropathy in a clinical trial conducted 
in colon cancer patients treated with FOLFOX therapy; however, its use in preventing neurotoxicity of OHP is currently not recommended. The utility of this agent in this clinical condition requires additional placebo-controlled studies [198].

\section{5- $\mathrm{HT}_{2 \mathrm{C}}$ receptor agonists}

Lorcaserin, a selective $5-\mathrm{HT}_{2 \mathrm{C}}$ receptor agonist, has effects on a range of physiological functions and behaviors. Lorcaserin also has potential clinically relevant effects in models of pain and seizure-like activities [199]. The first trial, a randomized phase II study, compared lorcaserin with duloxetine in the treatment of chronic OIPN (NCT03812523). The second study, a phase I open-label trial, investigated how well lorcaserin works in treating CIPN in stage I-IV gastrointestinal or breast cancer patients (NCT04205071).

\section{Non-pharmacological studies}

Extending the time of an intravenous drip to potentially avoid plasma peaks, rather than direct damage to nerve tissue, is possible [200]. Several clinical trials have been used in dose reductions in patients with incipient neuropathy signs/symptoms $\left(85 \mathrm{mg} / \mathrm{m}^{2} \mathrm{OHP}\right)$; when the neurologic examination was normal in the adjuvant setting, the dose reduction was from 85 to $75 \mathrm{mg} / \mathrm{m}^{2}$, and $65 \mathrm{mg} /$ $\mathrm{m}^{2}$ was applied in the metastatic setting [172]. The use of repetitive transcranial magnetic stimulation (rTMS) in headache and pain, and in other neurological and psychiatric conditions, has been proposed [173]. In a study, OIPN patients were randomized to be treated as follows: rTMS or sham rTMS over $30 \mathrm{~min}$ for 10 sessions over 10 business days, or standard of care (NCT03219502). Furthermore, change of lifestyle-related factors can aid in reducing or preventing the OIPN neurological side effects. The clinical study evaluated the effects of an exercise program designed to improve lower extremity balance and strength in OIPN persons with a specific purpose (NCT01422993), on their balance, strength, and neuropathic symptoms. However, the current evidence is weak to support the hypothesis, and serious limitations have been found in many studies reporting positive results [160]. The Non-Pharmacological Study also aimed at determining whether a polyamine-deprived diet (a specific nutritional therapy) can prevent acute OIPN in patients receiving FOLFOX4 (NCT01775449). Among herbal extracts, henna is used to treat diabetic cutaneous ulcers with small nerve fiber loss [174]. Moreover, the administration of different anticancer drugs, including OHP, also showed this pathological event, and the preliminary effects of henna on CIPN have been evaluated (NCT04201587).

\section{Outlook of future drug candidates}

OIPN prevention and treatment still needs additional preclinical studies, which can provide useful information for innovative research and future trials. The anti-inflammatory therapies, antioxidant therapies, neuroprotective and anti-allodynia agents, combined therapies, OHP dosage regulation agents, and herbal medicinal therapies involving stem cells and gut microbiota (probiotics) are all subjects of promising ongoing research. For the anti-inflammatory therapies, the anti-macrophage-derived high mobility group box 1 (HMGB1) neutralizing antibodies therapy decreased the neuropathy of OIPN by neuroinflammation modulation in an OIPN mice model [161]. The dual inhibitor (compound-DF2726A) of chemokine receptor CXCR1/ CXCR2 ligands was also studied in the OHP-induced neuropathy model [82]. Furthermore, the development of OHP-induced mechanical hypersensitivity was prevented by the administration of anti-CCL2 antibodies [121]. For the antioxidant therapies, our previous findings revealed that Nrf2 may have acted as a critical role in the progression of OIPN, with its ability of mitochondrial function protection and the inhibition of expression of the TRP protein family. The therapeutic or pharmacological activation of Nrf2 may be used to prevent or ameliorate the progression of OIPN without affecting the cytotoxicity of OHP [67, 80, 201]. Novel mitochondria-targeting antioxidants SS-31 prevented acute neuropathy symptoms caused by OHP in mice [164]. The neuroprotective agent niclosamide displayed potential antitumor and neuroprotective effects without affecting the cytotoxicity efficacy of OHP [202]. The $17 \alpha$ - hydroxyprogesterone caproate (HPGC), a synthetic derivative of progesterone, prevented the allodynia induced by OHP and glial activation in mice [201]. The anti-Parkinson's agent benztropine, an antidopamine and histamine reuptake inhibitor, reduced OIPN severity in the OHP mouse model, synergizing its anti-tumoral effect [118]. Thrombomodulin $\alpha$ prevented OIPN induced allodynia, most likely via a thrombin-dependent anti-neuropathic action [37]. A novel hyperpolarization-activated cyclic nucleotidegated channel $1(\mathrm{HCN} 1)$ inhibitor, MEL57A, recently demonstrated anti-hyperalgesic and anti-allodynic properties in OHP-treated rats [165]. The subcutaneously administered first-in-class potent analgesic compound cebranopadol (a.k.a. GRT-6005) reduced cold allodynia in the acute and the chronic phase of OIPN [166]. Mechanisms of CIPN overlap and can reinforce each other. The results of the hyperadditive effect with the combined subanalgesic doses of ambroxol and pregabalin indicated a synergistic reaction between the $\mathrm{Na}_{\mathrm{v}}$ and $\mathrm{Ca}_{\mathrm{v}}$ channel inhibitors in CIPN caused by OHP [64, 


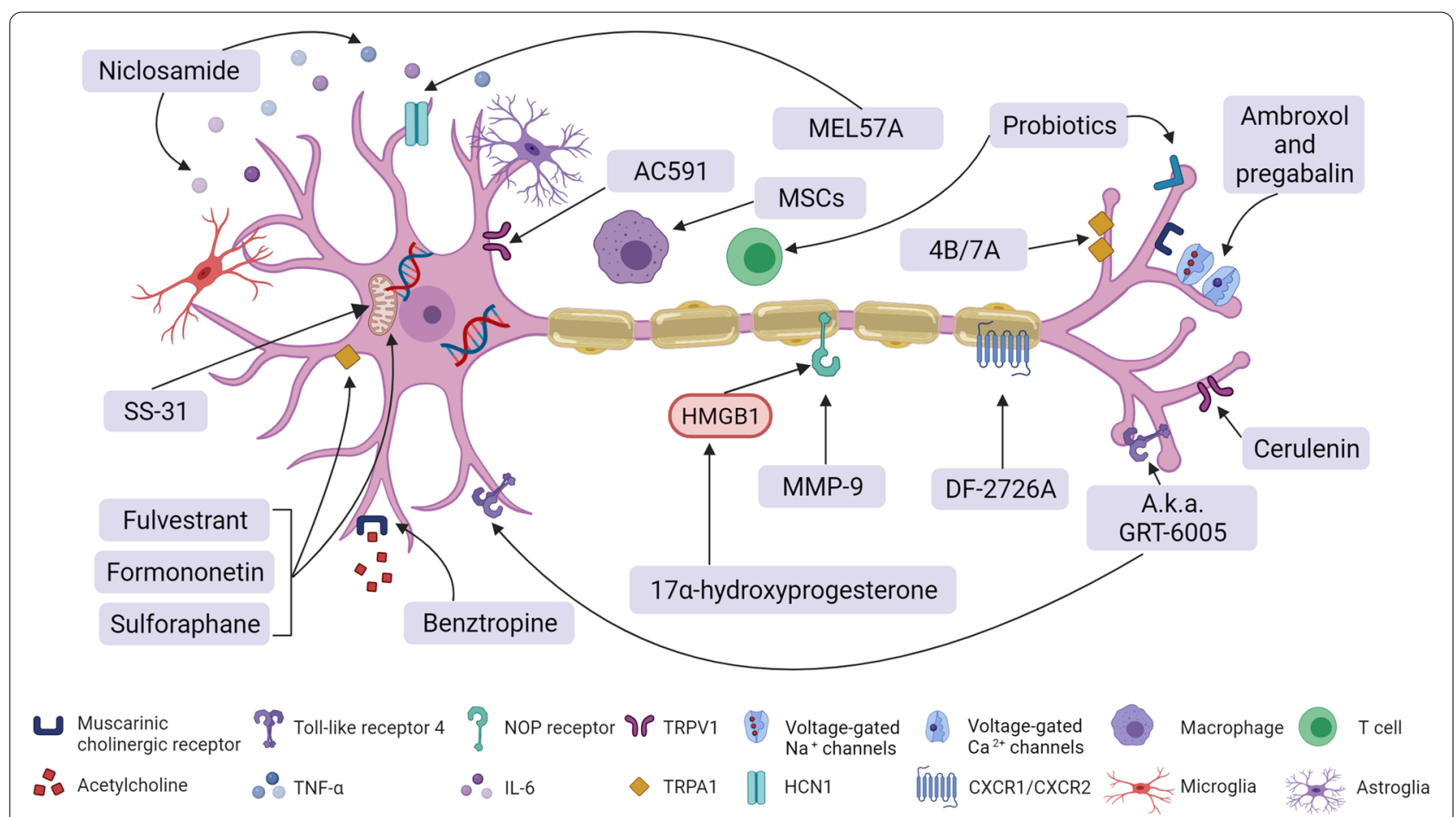

Fig. 4 Potential therapies for CIPN caused by oxaliplatin. Repurposed drugs and preclinically tested lead compounds for OIPN

167]. The dual phosphodiesterase $4 \mathrm{~B} / 7 \mathrm{~A}$ inhibitors and TRPA1 channel antagonists (HC-030031) reduced tactile allodynia in an OIPN model with TNF $\alpha$-lowering effect [168]. Combined therapy using "traditional" pharmacological agents and mesenchymal stem cells (MSCs) may also be important in the prevention and treatment of CIPN [203]. Based on the double action of OHP dosage in neuropathy and chemotherapeutic effect, some chemosensitizers such as cerulenin may enhance the therapeutic effects of OHP, and thus lower the OHP-induced neuropathy [204]; however, individual precision treatment strategies warrant further exploration [205]. Gut microbiota (probiotics) have shown therapeutic effects in various diseases, and previous studies have also evaluated their protective role in various nociceptive pain states [103, 171]; however, at present, little is known about their potential role and effect on OIPN. Herbal medicinal therapies (e.g., AC591, Acorus calamus, Camellia sinensi, Cannabis species, Curcuma longa, Ginkgo biloba, and Matricaria chamomilla) counteract the phenomena underlying CIPN, i.e., they attenuate inflammation and reduce oxidative stress in animals [206, 207]; however, their utility in the prevention or treatment of CIPN requires further investigation to confirm their safety and efficacy [208, 209]. Preclinical studies regarding potential future preventive therapies for OIPN are presented in Fig. 4.

\section{Conclusion}

Neuropathy is the most common side effect of oxaliplatin treatment and adversely affects patients' daily life and chemotherapy progress. Regarding the various signs and symptoms from different OIPN patients, there is an urgent need to find methods for accurate diagnosis of the severity of neuropathy. Developing the use of neuroimaging and QST combined with AI may have great value in the future diagnosis and treatment of OIPN. It is important to identify biological effects and risk factors of OIPN to appropriately treat neuropathy. Although no clear OIPN clinical biomarkers can be used to measure OIPN vulnerability, a detailed phenotyping approach (including psychophysical testing, validated patient self-report questionnaires, neuroimaging, and genetic testing) may move toward simple bedside tests as surrogate markers and improve clinical trials for CIPN. Many reported mechanisms listed above can lead to oxaliplatin-induced neuropathy. However, progress in OIPN treatment and prevention has been limited by the superficial understanding of the OIPN mechanism. Mechanisms rely on the unique structure and function of the neurons, and the reticular interaction between neurons, the immune system, and cancer cells must be considered. OIPN treatment should be followed-up with the newly discovered mechanism. 
An "ideal" OIPN agent should act as a multitarget agent to increase its neuropathy protective efficacy while not reducing the antitumor efficacy of the chemotherapy. Although there are some promising potential therapies for OIPN prevention and treatment, the need for improving the translation efficiency remains urgent. We need to draw lessons from previous failures in order to translate promising potential compounds into preclinical studies and early-phase clinical trials to expand clinical benefit. Moreover, the clinical trials also require design improvements, and careful attention should be paid to the clinical course and assessment methods of OIPN to gain useful and reliable information for prevention or treatment of severe side effects of OHP administration. Both the clinical evidence and preclinical studies need to include a critical appraisal of the quality and risk of bias. Issues such as blinding, prospectively defining the primary outcome measures, and proper sample size calculations should be considered [210]. Finally, identifying reliable biomarkers that can predict the OIPN clinical course will improve the clinical OIPN research toolkit. The relevance of the OIPN model to the clinical syndrome is also important, e.g., the behavioral assessment of spontaneous pain obtained by studying gender-specific rodents [211]. The prevention and treatment of OIPN remains an unmet and emergent clinical need. Further, to achieve effective and reliable results, high-quality research is mandatory.

In conclusion, OHP is a commonly used effective chemotherapy drug for digestive system tumors. Neuropathy is the most common side effect and exhibits doselimiting and life quality affecting characteristics. The OIPN problem demands strong translational approaches to achieve successful clinical application. Well-designed preclinical studies are needed, reflecting the clinical situation and careful considerations of the clinical trials design. Working together to standardize assessment techniques and ensuring that those that are used are validated robustly is important. The potential OIPN mechanisms are abundant and thus offer promising targets for novel therapies. A holistic approach is required, beyond traditionally predominant pharmacological interventions, and needs consideration of mechanistically driven nonpharmacological interventions. Although OIPN is a challenge not to be underestimated, collaboration both between countries and disciplines will be the key to success, with many potential barriers and rewards.

\section{Abbreviations}

ABCC2: ATP binding cassette subfamily C member 2; AGXT: Alanine glyoxylate aminotransfer-ase; Al: Artificial intelligence; Akt2: Protein kinase B; APE1: Apurinic/apyrimidinic endonuclease; ASCO: American Society of Clinical Oncology; ASCO: American Society of clinical Oncology; AT2: Angiotensin II type 2; ATP: Adenosine-triphosphate; ATP7A: ATPase Copper Transport-ing Alpha; BMI: Body mass index; Cava $2 \delta-1$ : Calcium voltage-gated calcium channel alpha2/ delta subunit; CCL2: C-C motif chemokine 2; CCR2: C-C-Motif Receptor 2; CD4 + : Cluster of Differentiation 4 receptors; CD8 +: Cluster of Differentiation 8 receptors; CIPN: Chemotherapy-induced peripheral neuropathy; CNS: Central nervous system; COX-2: Cyclooxygenase-2; CRC: Colorectal cancer; CTR1: Copper transport 1; CTRs: Copper transpo-rters; CXCR1: CXC chemokine receptor 1; CXCR2: CXC chemokine receptor 2; DDTC: Diethyldithiocarbamate; DNA: Deoxyribonucleic acid; DRG: Dorsal root ganglion; EAAT1: Recombinant Excitatory Amino Acid Transporter 1; EORTC: European Organization for Research and Treatment of Cancer; EPM: Electrophysiological measurements; ERK1/2: Extracellular regulated kinase1/2; GABA: $\gamma$-aminobutyric acid; GAT-1: GABA transporter subtype 1; GF: Germ-free; GFAP: Glial fibrillary acidic protein; GJG: Goshajinkigan; GLAST: Glutamate/aspart-ate transporter; GLT-1: Glutamate transporter-1; GM1: Monosialotetra-hexosylganglioside; GSTP1: Glutathione S-transferase pi 1; HCN1: Hyperpolarizationactivated cyclic nucleotide-gated channel 1; HCNs: Hyperpolarization-activated channels; HMGB1: High mobility group box 1; HPGC: Hydroxyprogesterone caproate; hTRPA1: Human TRPA1; IB: Investigator's Brochure; Iba1: Ionized calcium binding adapter molecule 1; IENFs: Intraepidermal nerve fibers; IL-8: Interleukin-8; INCAT: Inflammatory Neuropathy Cause and Treatment; JNK/Sapk: c-JunNH2-terminal kinase / stress activated protein kinase; K2P: Two pore potassium channels; KCNN3: Potassium channel SK3; LDI: Laser Doppler imager; LPS: Lipopolysaccharides; MAMPs: Microbe-associated molecular patterns; mISS: Group sensory sum score; MMP9: Matrix metallopeptidase 9; MnSOD: Manganese superoxide dismutase; MSCs: Mesenchymal stem cells; NCI-CTC: National Cancer InstituteCommon Toxicity Criteria; NGF: Mus musculus nerve growth factor; Nrf2: NF-E2 p45-related factor 2; OATP1B2: Organic aniontransporting polypeptide 1B2; OCT2: Recombinant Octamer Binding Transcription Factor 2; OCTN2: Organic cation transporter-2; OCTs: Organic cation transport-ters; OHP: Oxaliplatin; OIPN: Oxaliplatin-induced peripheral neurotoxicity; OXA: Oxaliplatin; PI3K: Phosphatidylinositide 3-kinases; PKC: Protein kinase C; PO: Per os; p38: Phosphoprotein 38; QST: Quantitative sensory tests; ROS: Reactive oxygen species; rhuLIF: Recombinant human leukemia inhibitory factor; rTMS: Repetitive transcranial magnetic stimulation; S1P: Sphingosine-1-phosphate; Sapk: Stress activated protein kinase; SK3: Small-conductance calcium-activated potassium channel 3; SNRI: Serotonin-noradrenaline reuptake inhibitor; SPF: Specified Pathogen Free; S1P2: Sphingosine-1-phosphate receptor2; S1PR1: Sphingosine-1-Phosphate Receptor 1; TLR: Toll-like receptors; TLR4: Toll-like receptors 4; TNSc: Total Neuropathy Score clinical version; TRAAK: TWIK-related arachidonic acid-stimulated K+ channel; TREK-1: TWIK-Related K+Channel 1; TRPA 1: TRP ankyrin 1; TRPM8: Transient receptor potential cation channel, subfamily $M$, member 8 .

\section{Acknowledgements}

Figures 1, 2, 3 and 4 in this review were created using BioRender.com (https:// biorender.com).

\section{Authors' contributions}

$Y Y$ contributed to conception and manuscript design. $Y Y, B Z, X G, J Y$, JL and JS were all involved in manuscript preparation, revision and critique of the manuscript for important intellectual content. YY and PC were involved in funding acquisition. The authors read and approved the final manuscript.

\section{Funding}

This work was supported by the National Natural Science Foundation of China [grant numbers 81973498 and 81774283], National Science Foundation For Distinguished Young Scholars [grant numbers 82125037], the Joint Open Project of Jiangsu Key Laboratory for Pharmacology and Safety Evaluation of Chinese Materia Medica and Yangtze River Pharmaceutical Group (No. JKLPSE202003), Suzhou Clinical Key Disease Diagnosis and Treatment Technology foundation (LCZX201823), Suzhou Science and Technology Development Program (SYS2020058) and Changshu Science and Technology Development Program (CS202029).

Availability of data and materials Not applicable.

\section{Declarations}

Ethics approval and consent to participate Not applicable. 


\section{Consent for publication \\ Not applicable.}

\section{Competing interests}

The authors declare that they have no competing interests.

\begin{abstract}
Author details
${ }^{1}$ Affiliated Hospital of Integrated Traditional Chinese and Western Medicine, Nanjing University of Chinese Medicine, 100\#, Hongshan Road, Nanjing 210028, Jiangsu, China. ${ }^{2}$ Department of Pharmacology, School of Pharmacy, Nanjing University of Chinese Medicine, Nanjing 210023, China. ${ }^{3}$ Jiangsu Key Laboratory for Pharmacology and Safety Evaluation of Chinese Materia Medica, Nanjing University of Chinese Medicine, Nanjing 210023, China. ${ }^{4}$ Yangtze River Pharmaceutical Group, Taizhou 225321, China. ${ }^{5}$ Changshu No.1 People's Hospital Affiliated to Soochow University, Changshu 215500, China. ${ }^{6}$ Department of Pharmacy, The First Affiliated Hospital of Zhengzhou University, Zhengzhou, Henan 450052, P.R. China. ${ }^{7}$ Zhenjiang Hospital of Chinese Traditional and Western Medicine, Zhenjiang, 212002, Jiangsu, China.
\end{abstract}

Received: 22 July 2021 Accepted: 12 October 2021

Published online: 22 October 2021

\section{References}

1. Loprinzi CL, Lacchetti C, Bleeker J, Cavaletti G, Chauhan C, Hertz DL, et al. Prevention and management of chemotherapy-induced peripheral neuropathy in survivors of adult cancers: ASCO guideline update. J Clin Oncol. 2020;38:3325-48.

2. Colvin LA. Chemotherapy-induced peripheral neuropathy: where are we now? Pain. 2019;160(Suppl 1):S1-S10

3. Brozou V, Vadalouca A, Zis P. Pain in platin-induced neuropathies: a systematic review and meta-analysis. Pain Ther. 2018;7:105-19.

4. Seretny M, Currie GL, Sena ES, Ramnarine S, Grant R, MacLeod MR, et al. Incidence, prevalence, and predictors of chemotherapy-induced peripheral neuropathy: a systematic review and meta-analysis. Pain. 2014;155:2461-70.

5. Li GZ, Hu YH, Li DY, Zhang Y, Guo HL, Li YM, et al. Vincristineinduced peripheral neuropathy: a mini-review. Neurotoxicology. 2020;81:161-71.

6. Ibrahim EY, Ehrlich BE. Prevention of chemotherapy-induced peripheral neuropathy: a review of recent findings. Crit Rev Oncol Hematol. 2020;145:102831.

7. Pachman DR, Qin R, Seisler DK, Smith EM, Beutler AS, Ta LE, et al. Clinical course of oxaliplatin-induced neuropathy: results from the randomized phase III trial N08CB (alliance). J Clin Oncol. 2015;33:3416-22.

8. Aubin F, Carbonnel F, Wendling D. The complexity of adverse sideeffects to biological agents. J Crohns Colitis. 2013;7:257-62.

9. Mason JM, Rees GJ. Oxaliplatin-induced acute thrombocytopenia. J Oncol Pharm Pract. 2011;17:433-5.

10. Han CH, Kilfoyle DH, Hill AG, Jameson MB, McKeage MJ. Preventing oxaliplatin-induced neurotoxicity: rationale and design of phase Ib randomized, double-blind, placebo-controlled, cross-over trials for early clinical evaluation of investigational therapeutics. Expert Opin Drug Metab Toxicol. 2016;12:1479-90.

11. Ewertz M, Qvortrup C, Eckhoff L. Chemotherapy-induced peripheral neuropathy in patients treated with taxanes and platinum derivatives. Acta Oncol. 2015;54:587-91.

12. Grolleau F, Gamelin L, Boisdron-Celle M, Lapied B, Pelhate M, Gamelin E. A possible explanation for a neurotoxic effect of the anticancer agent oxaliplatin on neuronal voltage-gated sodium channels. J Neurophysiol. 2001;85:2293-7.

13. Lehky TJ, Leonard GD, Wilson RH, Grem JL, Floeter MK. Oxaliplatininduced neurotoxicity: acute hyperexcitability and chronic neuropathy. Muscle Nerve. 2004;29:387-92.

14. Alberti P, Canta A, Chiorazzi A, Fumagalli G, Meregalli C, Monza L, et al. Topiramate prevents oxaliplatin-related axonal hyperexcitability and oxaliplatin induced peripheral neurotoxicity. Neuropharmacology. 2020;164:107905
15. Beijers AJ, Mols F, Vreugdenhil G. A systematic review on chronic oxaliplatin-induced peripheral neuropathy and the relation with oxaliplatin administration. Support Care Cancer. 2014;22:1999-2007.

16. Griffith KA, Zhu S, Johantgen M, Kessler MD, Renn C, Beutler AS, et al. Oxaliplatin-induced peripheral neuropathy and identification of unique severity groups in colorectal cancer. J Pain Symptom Manag. 2017; 54:701-706.e701.

17. Ventzel $L$, Jensen AB, Jensen AR, Jensen TS, Finnerup NB. Chemotherapy-induced pain and neuropathy: a prospective study in patients treated with adjuvant oxaliplatin or docetaxel. Pain. 2016;157:560-8.

18. de Gramont A, Figer A, Seymour M, Homerin M, Hmissi A, Cassidy J, et al. Leucovorin and fluorouracil with or without oxaliplatin as first-line treatment in advanced colorectal cancer. J Clin Oncol. 2000;18:2938-47.

19. Miaskowski C, Mastick J, Paul SM, Topp K, Smoot B, Abrams G, et al. Chemotherapy-induced neuropathy in cancer survivors. J Pain Symptom Manag. 2017:54:204-18 e202.

20. Staff NP, Cavaletti G, Islam B, Lustberg M, Psimaras D, Tamburin S. Platinum-induced peripheral neurotoxicity: from pathogenesis to treatment. J Peripher Nerv Syst. 2019;24(Suppl 2):S26-39.

21. Kanat O, Ertas H, Caner B. Platinum-induced neurotoxicity: a review of possible mechanisms. World J Clin Oncol. 2017:8:329-35.

22. Sharma S, Venkitaraman R, Vas PR, Rayman G. Assessment of chemotherapy-induced peripheral neuropathy using the LDIFLARE technique: a novel technique to detect neural small fiber dysfunction. Brain Behav. 2015;5:e00354.

23. Trotti A, Colevas AD, Setser A, Rusch V, Jaques D, Budach V, et al. CTCAE v3.0: development of a comprehensive grading system for the adverse effects of cancer treatment. Semin Radiat Oncol. 2003;13:176-81.

24. Cornblath DR, Chaudhry V, Carter K, Lee D, Seysedadr M, Miernicki M, et al. Total neuropathy score: validation and reliability study. Neurology. 1999:53:1660-4

25. Merkies IS, Schmitz PI, van der Meche FG, van Doorn PA. Psychometric evaluation of a new sensory scale in immune-mediated polyneuropathies. Inflammatory Neuropathy Cause and Treatment (INCAT) Group. Neurology. 2000;54:943-9.

26. Wolf SL, Barton DL, Qin R, Wos EJ, Sloan JA, Liu H, et al. The relationship between numbness, tingling, and shooting/burning pain in patients with chemotherapy-induced peripheral neuropathy (CIPN) as measured by the EORTC QLQ-CIPN20 instrument, N06CA. Support Care Cancer. 2012;20:625-32.

27. Aaronson NK, Ahmedzai S, Bergman B, Bullinger M, Cull A, Duez NJ, et al. The European Organization for Research and Treatment of Cancer QLQ-C30: a quality-of-life instrument for use in international clinical trials in oncology. J Natl Cancer Inst. 1993;85:365-76.

28. Lauria G. Small fibre neuropathies. Curr Opin Neurol. 2005;18:591-7.

29. Ferdousi M, Azmi S, Petropoulos IN, Fadavi H, Ponirakis G, Marshall A, et al. Corneal confocal microscopy detects small fibre neuropathy in patients with upper gastrointestinal cancer and nerve regeneration in chemotherapy induced peripheral neuropathy. PLoS One. 2015;10:e0139394.

30. Heuvel S, Doorduin J, Steegers MAH, Bronkhorst EM, Radema SA, Vissers $\mathrm{KCP}$, et al. Simple surface EMG recording as a noninvasive screening method for the detection of acute oxaliplatin-induced neurotoxicity: a feasibility pilot study. Neurosci Lett. 2019;699:184-8.

31. Dilsizian SE, Siegel EL. Artificial intelligence in medicine and cardiac imaging: harnessing big data and advanced computing to provide personalized medical diagnosis and treatment. Curr Cardiol Rep. 2014;16:441.

32. Hamet P, Tremblay J. Artificial intelligence in medicine. Metabolism 2017:695:S36-40.

33. Haanpaa M, Attal N, Backonja M, Baron R, Bennett M, Bouhassira D, et al. NeuPSIG guidelines on neuropathic pain assessment. Pain. 2011;152:14-27.

34. van Hecke O, Kamerman PR, Attal N, Baron R, Bjornsdottir G, Bennett DLH, et al. Neuropathic pain phenotyping by international consensus (NeuroPPIC) for genetic studies: a NeuPSIG systematic review, Delphi survey, and expert panel recommendations. Pain. 2015;156:2337-53.

35. Cavaletti G, Alberti P, Argyriou AA, Lustberg M, Staff NP, Tamburin S, et al. Chemotherapy-induced peripheral neurotoxicity: a multifaceted, still unsolved issue. J Peripher Nerv Syst. 2019;24(Suppl 2):S6-S12. 
36. Meregalli C, Fumagalli G, Alberti P, Canta A, Chiorazzi A, Monza L, et al. Neurofilament light chain: a specific serum biomarker of axonal damage severity in rat models of chemotherapy-induced peripheral neurotoxicity. Arch Toxicol. 2020;94:2517-22.

37. Tsubota M, Fukuda R, Hayashi Y, Miyazaki T, Ueda S, Yamashita R, et al. Role of non-macrophage cell-derived HMGB1 in oxaliplatin-induced peripheral neuropathy and its prevention by the thrombin/thrombomodulin system in rodents: negative impact of anticoagulants. J Neuroinflammation. 2019;16:199.

38. Roldan CJ, Johnson C, Lee SO, Peng A, Dougherty PM, Huh B. Subclinical peripheral neuropathy in patients with head and neck cancer: a quantitative sensory testing (QST) study. Pain Physician. 2018;21:E419-27.

39. de Carvalho BM, Kosturakis AK, Eng C, Wendelschafer-Crabb G, Kennedy WR, Simone DA, et al. A quantitative sensory analysis of peripheral neuropathy in colorectal cancer and its exacerbation by oxaliplatin chemotherapy. Cancer Res. 2014;74:5955-62.

40. Attal N, Bouhassira D, Gautron M, Vaillant JN, Mitry E, Lepere C, et al. Thermal hyperalgesia as a marker of oxaliplatin neurotoxicity: a prospective quantified sensory assessment study. Pain. 2009;144:245-52.

41. Park SB, Kwok JB, Asher R, Lee CK, Beale P, Selle F, et al. Clinical and genetic predictors of paclitaxel neurotoxicity based on patient- versus clinician-reported incidence and severity of neurotoxicity in the ICON7 trial. Ann Oncol. 2017;28:2733-40.

42. Sanchez-Barroso L, Apellaniz-Ruiz M, Gutierrez-Gutierrez G, Santos $\mathrm{M}$, Roldan-Romero JM, Curras M, et al. Concomitant medications and risk of chemotherapy-induced peripheral neuropathy. Oncologist. 2019;24:e784-92.

43. Shah A, Hoffman EM, Mauermann ML, Loprinzi CL, Windebank AJ, Klein $\mathrm{CJ}$, et al. Incidence and disease burden of chemotherapy-induced peripheral neuropathy in a population-based cohort. J Neurol Neurosurg Psychiatry. 2018;89:636-41.

44. Leblanc AF, Sprowl JA, Alberti P, Chiorazzi A, Arnold WD, Gibson AA, et al. OATP1B2 deficiency protects against paclitaxel-induced neurotoxicity. J Clin Invest. 2018;128:816-25.

45. Lee KH, Chang HJ, Han SW, Oh DY, Im SA, Bang YJ, et al. Pharmacogenetic analysis of adjuvant FOLFOX for Korean patients with colon cancer. Cancer Chemother Pharmacol. 2013;71:843-51.

46. Johnson C, Pankratz VS, Velazquez Al, Aakre JA, Loprinzi CL, Staff NP, et al. Candidate pathway-based genetic association study of platinum and platinum-taxane related toxicity in a cohort of primary lung cancer patients. J Neurol Sci. 2015;349:124-8.

47. Qian CY, Zheng Y, Wang Y, Chen J, Liu JY, Zhou HH, et al. Associations of genetic polymorphisms of the transporters organic cation transporter 2 (OCT2), multidrug and toxin extrusion 1 (MATE1), and ATP-binding cassette subfamily $\mathrm{C}$ member 2 ( $\mathrm{ABCC}$ ) with platinum-based chemotherapy response and toxicity in non-small cell lung cancer patients. Chin J Cancer. 2016;35:85.

48. Sprowl JA, Ciarimboli G, Lancaster CS, Giovinazzo H, Gibson AA, Du G, et al. Oxaliplatin-induced neurotoxicity is dependent on the organic cation transporter OCT2. Proc Natl Acad Sci U S A. 2013;1 10:11199-204.

49. Mori Y, Katsumata K, Tsuchida A, Aoki T. Single nucleotide polymorphism analysis in the GSTP1 and ABCC2 genes about neuropathy by the Oxaliplatin. Gan To Kagaku Ryoho. 2008;35:2377-81.

50. Gamelin L, Capitain O, Morel A, Dumont A, Traore S, Anne LB, et al. Predictive factors of oxaliplatin neurotoxicity: the involvement of the oxalate outcome pathway. Clin Cancer Res. 2007;13:6359-68.

51. Argyriou AA, Cavaletti G, Antonacopoulou A, Genazzani AA, Briani C, Bruna J, et al. Voltage-gated sodium channel polymorphisms play a pivotal role in the development of oxaliplatin-induced peripheral neurotoxicity: results from a prospective multicenter study. Cancer. 2013;119:3570-7.

52. Sereno M, Gutierrez-Gutierrez G, Rubio JM, Apellaniz-Ruiz M, SanchezBarroso L, Casado E, et al. Genetic polymorphisms of SCN9A are associated with oxaliplatin-induced neuropathy. BMC Cancer. 2017;17:63.

53. Marmiroli P, Riva B, Pozzi E, Ballarini E, Lim D, Chiorazzi A, et al. Susceptibility of different mouse strains to oxaliplatin peripheral neurotoxicity: phenotypic and genotypic insights. PLoS One. 2017;12:e0186250.
54. Cliff J, Jorgensen AL, Lord R, Azam F, Cossar L, Carr DF, et al. The molecular genetics of chemotherapy-induced peripheral neuropathy: a systematic review and meta-analysis. Crit Rev Oncol Hematol. 2017;120:127-40.

55. Sittl R, Lampert A, Huth T, Schuy ET, Link AS, Fleckenstein J, et al. Anticancer drug oxaliplatin induces acute cooling-aggravated neuropathy via sodium channel subtype $\mathrm{Na}(\mathrm{V})$ 1.6-resurgent and persistent current. Proc Natl Acad Sci U S A. 2012;109:6704-9.

56. Egashira N, Hirakawa S, Kawashiri T, Yano T, Ikesue H, Oishi R. Mexiletine reverses oxaliplatin-induced neuropathic pain in rats. J Pharmacol Sci. 2010;112:473-6

57. Avan A, Postma TJ, Ceresa C, Avan A, Cavaletti G, Giovannetti E, et al. Platinum-induced neurotoxicity and preventive strategies: past, present, and future. Oncologist. 2015;20:411-32.

58. Chen HP, Zhou W, Kang LM, Yan H, Zhang L, Xu BH, et al. Intrathecal miR-96 inhibits Nav1.3 expression and alleviates neuropathic pain in rat following chronic construction injury. Neurochem Res. 2014;39:76-83.

59. Kagiava A, Tsingotjidou A, Emmanouilides C, Theophilidis G. The effects of oxaliplatin, an anticancer drug, on potassium channels of the peripheral myelinated nerve fibres of the adult rat. Neurotoxicology. 2008;29:1100-6.

60. Kerckhove N, Busserolles J, Stanbury T, Pereira B, Plence V, Bonnetain $F$, et al. Effectiveness assessment of riluzole in the prevention of oxaliplatin-induced peripheral neuropathy: RILUZOX-01: protocol of a randomised, parallel, controlled, double-blind and multicentre study by the UNICANCER-AFSOS Supportive Care intergroup. BMJ Open. 2019;9:e027770.

61. Poupon L, Lamoine S, Pereira V, Barriere DA, Lolignier S, Giraudet F, et al. Targeting the TREK-1 potassium channel via riluzole to eliminate the neuropathic and depressive-like effects of oxaliplatin. Neuropharmacology. 2018;140:43-61.

62. Anon B, Largeau B, Girault A, Chantome A, Caulet M, Perray C, et al. Possible association of CAG repeat polymorphism in KCNN3 encoding the potassium channel SK3 with oxaliplatin-induced neurotoxicity. Cancer Chemother Pharmacol. 2018;82:149-57.

63. Siau C, Bennett GJ. Dysregulation of cellular calcium homeostasis in chemotherapy-evoked painful peripheral neuropathy. Anesth Analg. 2006:102:1485-90.

64. Furgala A, Fijalkowski L, Nowaczyk A, Salat R, Salat K. Time-shifted co-administration of sub-analgesic doses of ambroxol and pregabalin attenuates oxaliplatin-induced cold allodynia in mice. Biomed Pharmacother. 2018;106:930-40.

65. Yamamoto K, Tsuboi M, Kambe T, Abe K, Nakatani Y, Kawakami K, et al. Oxaliplatin administration increases expression of the voltage-dependent calcium channel alpha2delta-1 subunit in the rat spinal cord. J Pharmacol Sci. 2016:130:117-22.

66. Schmitt LI, Leo M, Kleinschnitz C, Hagenacker T. Oxaliplatin modulates the characteristics of voltage-gated calcium channels and action potentials in small dorsal root ganglion neurons of rats. Mol Neurobiol. 2018:55:8842-55.

67. Yang Y, Luo L, Cai X, Fang Y, Wang J, Chen G, et al. Nrf2 inhibits oxaliplatin-induced peripheral neuropathy via protection of mitochondrial function. Free Radic Biol Med. 2018;120:13-24.

68. Anand U, Otto WR, Anand P. Sensitization of capsaicin and icilin responses in oxaliplatin treated adult rat DRG neurons. Mol Pain. 2010;6:82.

69. Gauchan P, Andoh T, Kato A, Kuraishi Y. Involvement of increased expression of transient receptor potential melastatin 8 in oxaliplatininduced cold allodynia in mice. Neurosci Lett. 2009;458:93-5.

70. Miyake T, Nakamura S, Meng Z, Hamano S, Inoue K, Numata T, et al. Distinct mechanism of cysteine oxidation-dependent activation and cold sensitization of human transient receptor potential Ankyrin 1 channel by high and low Oxaliplatin. Front Physiol. 2017;8:878.

71. Nakagawa T, Kaneko S. Roles of transient receptor potential Ankyrin 1 in Oxaliplatin-induced peripheral neuropathy. Biol Pharm Bull. 2017:40:947-53.

72. Cavaletti G, Ceresa C, Nicolini G, Marmiroli P. Neuronal drug transporters in platinum drugs-induced peripheral neurotoxicity. Anticancer Res. 2014;34:483-6. 
73. Holmes J, Stanko J, Varchenko M, Ding H, Madden VJ, Bagnell CR, et al. Comparative neurotoxicity of oxaliplatin, cisplatin, and ormaplatin in a Wistar rat model. Toxicol Sci. 1998;46:342-51.

74. McWhinney SR, Goldberg RM, McLeod HL. Platinum neurotoxicity pharmacogenetics. Mol Cancer Ther. 2009;8:10-6.

75. Podratz JL, Knight AM, Ta LE, Staff NP, Gass JM, Genelin K, et al. Cisplatin induced mitochondrial DNA damage in dorsal root ganglion neurons. Neurobiol Dis. 2011;41:661-8.

76. Nassini R, Gees M, Harrison S, De Siena G, Materazzi S, Moretto N, et al. Oxaliplatin elicits mechanical and cold allodynia in rodents via TRPA 1 receptor stimulation. Pain. 2011;152:1621-31.

77. Chine VB, Au NPB, Kumar G, Ma CHE. Targeting axon integrity to prevent chemotherapy-induced peripheral neuropathy. Mol Neurobiol. 2019;56:3244-59.

78. Lim SC, Choi JE, Kang HS, Han SI. Ursodeoxycholic acid switches oxaliplatin-induced necrosis to apoptosis by inhibiting reactive oxygen species production and activating p53-caspase 8 pathway in HepG2 hepatocellular carcinoma. Int J Cancer. 2010;126:1582-95.

79. Zheng $\mathrm{H}$, Xiao WH, Bennett GJ. Functional deficits in peripheral nerve mitochondria in rats with paclitaxel- and oxaliplatin-evoked painful peripheral neuropathy. Exp Neurol. 2011;232:154-61.

80. Fang Y, Ye J, Zhao B, Sun J, Gu N, Chen X, et al. Formononetin ameliorates oxaliplatin-induced peripheral neuropathy via the KEAP1-NRF2GSTP1 axis. Redox Biol. 2020;36:101677.

81. Maruta T, Nemoto T, Hidaka K, Koshida T, Shirasaka T, Yanagita T, et al. Upregulation of ERK phosphorylation in rat dorsal root ganglion neurons contributes to oxaliplatin-induced chronic neuropathic pain. PLoS One. 2019;14:e0225586.

82. Brandolini L, Castelli V, Aramini A, Giorgio C, Bianchini G, Russo R, et al. DF2726A, a new IL-8 signalling inhibitor, is able to counteract chemotherapy-induced neuropathic pain. Sci Rep. 2019;9:11729.

83. Shen S, Lim G, You Z, Ding W, Huang P, Ran C, et al. Gut microbiota is critical for the induction of chemotherapy-induced pain. Nat Neurosci. 2017;20:1213-6.

84. Makker PG, Duffy SS, Lees JG, Perera CJ, Tonkin RS, Butovsky O, et al. Characterisation of immune and neuroinflammatory changes associated with chemotherapy-induced peripheral neuropathy. PLoS One. 2017;12:e0170814.

85. Raghavendra V, Tanga F, DeLeo JA. Inhibition of microglial activation attenuates the development but not existing hypersensitivity in a rat model of neuropathy. J Pharmacol Exp Ther. 2003;306:624-30.

86. Zhang T, Zhang J, Shi J, Feng Y, Sun ZS, Li H. Antinociceptive synergistic effect of spinal mGluR2/3 antagonist and glial cells inhibitor on peripheral inflammation-induced mechanical hypersensitivity. Brain Res Bull. 2009;79:219-23.

87. Di Cesare Mannelli L, Pacini A, Matera C, Zanardelli M, Mello T, De Amici M, et al. Involvement of alpha7 nAChR subtype in rat oxaliplatininduced neuropathy: effects of selective activation. Neuropharmacology. 2014;79:37-48.

88. Di Cesare Mannelli L, Pacini A, Micheli L, Tani A, Zanardelli M, Ghelardini C. Glial role in oxaliplatin-induced neuropathic pain. Exp Neurol. 2014;261:22-33.

89. Di Cesare Mannelli L, Pacini A, Bonaccini L, Zanardelli M, Mello T, Ghelardini C. Morphologic features and glial activation in rat oxaliplatindependent neuropathic pain. J Pain. 2013;14:1585-600.

90. Imai S, Koyanagi M, Azimi Z, Nakazato Y, Matsumoto M, Ogihara T, et al. Taxanes and platinum derivatives impair Schwann cells via distinct mechanisms. Sci Rep. 2017;7:5947.

91. Salat K, Kolaczkowski M, Furgala A, Rojek A, Sniecikowska J, Varney MA, et al. Antinociceptive, antiallodynic and antihyperalgesic effects of the 5-HT1A receptor selective agonist, NLX-112 in mouse models of pain. Neuropharmacology. 2017;125:181-8.

92. Hache G, Guiard BP, Nguyen TH, Quesseveur G, Gardier AM, Peters $D$, et al. Antinociceptive activity of the new triple reuptake inhibitor NS18283 in a mouse model of chemotherapy-induced neuropathic pain. Eur J Pain. 2015;19:322-33.

93. Potenzieri A, Riva B, Genazzani AA. Unexpected Ca(2+)-mobilization of oxaliplatin via $\mathrm{H} 1$ histamine receptors. Cell Calcium. 2020;86:102128.

94. Yamamoto S, Ushio S, Egashira N, Kawashiri T, Mitsuyasu S, Higuchi $\mathrm{H}$, et al. Excessive spinal glutamate transmission is involved in oxaliplatin-induced mechanical allodynia: a possibility for riluzole as a prophylactic drug. Sci Rep. 2017;7:9661.

95. Soni N, Reddy BV, Kumar P. GLT-1 transporter: an effective pharmacological target for various neurological disorders. Pharmacol Biochem Behav. 2014;127:70-81.

96. Ta LE, Espeset L, Podratz J, Windebank AJ. Neurotoxicity of oxaliplatin and cisplatin for dorsal root ganglion neurons correlates with platinumDNA binding. Neurotoxicology. 2006;27:992-1002.

97. Norcini M, Vivoli E, Galeotti N, Bianchi E, Bartolini A, Ghelardini C. Supraspinal role of protein kinase $C$ in oxaliplatin-induced neuropathy in rat. Pain. 2009;146:141-7.

98. Jiang SP, Zhang ZD, Kang LM, Wang QH, Zhang L, Chen HP. Celecoxib reverts oxaliplatin-induced neuropathic pain through inhibiting PI3K/Akt2 pathway in the mouse dorsal root ganglion. Exp Neurol. 2016;275(Pt 1):11-6.

99. Ito N, Sakai A, Miyake N, Maruyama M, Iwasaki H, Miyake K, et al. Suzuki $\mathrm{H}$ : miR-15b mediates oxaliplatin-induced chronic neuropathic pain through BACE1 down-regulation. Br J Pharmacol. 2017;174:386-95.

100. Schafers M, Sorkin L. Effect of cytokines on neuronal excitability. Neurosci Lett. 2008:437:188-93.

101. Trevisan G, Materazzi S, Fusi C, Altomare A, Aldini G, Lodovici M, et al. Novel therapeutic strategy to prevent chemotherapy-induced persistent sensory neuropathy by TRPA 1 blockade. Cancer Res. 2013;73:3120-31.

102. Meseguer V, Alpizar YA, Luis E, Tajada S, Denlinger B, Fajardo O, et al. TRPA1 channels mediate acute neurogenic inflammation and pain produced by bacterial endotoxins. Nat Commun. 2014;5:3125.

103. Zhong S, Zhou Z, Liang Y, Cheng X, Li Y, Teng W, et al. Targeting strategies for chemotherapy-induced peripheral neuropathy: does gut microbiota play a role? Crit Rev Microbiol. 2019;45:369-93.

104. Gui QF, Lu HF, Zhang CX, Xu ZR, Yang YH. Well-balanced commensal microbiota contributes to anti-cancer response in a lung cancer mouse model. Genet Mol Res. 2015;14:5642-51.

105. Deuis JR, Zimmermann K, Romanovsky AA, Possani LD, Cabot PJ, Lewis RJ, et al. An animal model of oxaliplatin-induced cold allodynia reveals a crucial role for Nav1.6 in peripheral pain pathways. Pain. 2013;154:1749-57.

106. Lainez S, Tsantoulas C, Biel M, McNaughton PA. HCN3 ion channels: roles in sensory neuronal excitability and pain. J Physiol. 2019;597:4661-75.

107. Starobova H, Vetter I. Pathophysiology of chemotherapy-induced peripheral neuropathy. Front Mol Neurosci. 2017;10:174.

108. Sittl R, Carr RW, Fleckenstein J, Grafe P. Enhancement of axonal potassium conductance reduces nerve hyperexcitability in an in vitro model of oxaliplatin-induced acute neuropathy. Neurotoxicology. 2010:31:694-700.

109. Materazzi S, Fusi C, Benemei S, Pedretti P, Patacchini R, Nilius B, et al. TRPA1 and TRPV4 mediate paclitaxel-induced peripheral neuropathy in mice via a glutathione-sensitive mechanism. Pflugers Arch. 2012;463:561-9.

110. Wahl P, Foged C, Tullin S, Thomsen C. Iodo-resiniferatoxin, a new potent vanilloid receptor antagonist. Mol Pharmacol. 2001;59:9-15.

111. Carozzi VA, Canta A, Chiorazzi A. Chemotherapy-induced periphera neuropathy: what do we know about mechanisms? Neurosci Lett. 2015;596:90-107.

112. Liu JJ, Jamieson SM, Subramaniam J, Ip V, Jong NN, Mercer JF, et al. Neuronal expression of copper transporter 1 in rat dorsal root ganglia: association with platinum neurotoxicity. Cancer Chemother Pharmacol. 2009;64:847-56.

113. Jimenez-Andrade JM, Herrera MB, Ghilardi JR, Vardanyan M, Melemedjian OK, Mantyh PW. Vascularization of the dorsal root ganglia and peripheral nerve of the mouse: implications for chemical-induced peripheral sensory neuropathies. Mol Pain. 2008;4:10.

114. Streckmann F, Balke M, Lehmann HC, Rustler V, Koliamitra C, Elter T, et al. The preventive effect of sensorimotor- and vibration exercises on the onset of Oxaliplatin- or vinca-alkaloid induced peripheral neuropathies - STOP. BMC Cancer. 2018;18:62.

115. Miao F, Wang R, Cui G, Li X, Wang T, Li X. Engagement of MicroRNA-155 in exaggerated oxidative stress signal and TRPA 1 in the dorsal horn of the spinal cord and neuropathic pain during chemotherapeutic Oxaliplatin. Neurotox Res. 2019;36:712-23. 
116. Chukyo A, Chiba T, Kambe T, Yamamoto K, Kawakami K, Taguchi K, et al. Oxaliplatin-induced changes in expression of transient receptor potential channels in the dorsal root ganglion as a neuropathic mechanism for cold hypersensitivity. Neuropeptides. 2018;67:95-101.

117. Miyake T, Nakamura S, Zhao M, So K, Inoue K, Numata T, et al. Cold sensitivity of TRPA 1 is unveiled by the prolyl hydroxylation blockadeinduced sensitization to ROS. Nat Commun. 2016:7:12840.

118. Cerles O, Goncalves TC, Chouzenoux S, Benoit E, Schmitt A, Bennett Saidu NE, et al. Preventive action of benztropine on platinum-induced peripheral neuropathies and tumor growth. Acta Neuropathol Commun. 2019;7:9.

119. Bobylev I, Joshi AR, Barham M, Neiss WF, Lehmann HC. Depletion of Mitofusin-2 causes mitochondrial damage in cisplatin-induced neuropathy. Mol Neurobiol. 2018;55:1227-35.

120. Zheng $\mathrm{H}$, Xiao WH, Bennett GJ. Mitotoxicity and bortezomib-induced chronic painful peripheral neuropathy. Exp Neurol. 2012;238:225-34.

121. Illias AM, Gist AC, Zhang H, Kosturakis AK, Dougherty PM. Chemokine CCL2 and its receptor CCR2 in the dorsal root ganglion contribute to oxaliplatin-induced mechanical hypersensitivity. Pain. 2018;159:1308-16.

122. Gu H, Wang C, Li J, Yang Y, Sun W, Jiang C, et al. High mobility group box-1-toll-like receptor 4-phosphatidylinositol 3-kinase/protein kinase B-mediated generation of matrix metalloproteinase-9 in the dorsal root ganglion promotes chemotherapy-induced peripheral neuropathy. Int J Cancer. 2020;146:2810-21.

123. Stojanovska V, McQuade RM, Fraser S, Prakash M, Gondalia S, Stavely $R$, et al. Oxaliplatin-induced changes in microbiota, TLR4+ cells and enhanced HMGB1 expression in the murine colon. PLOS One. 2018;13:e0198359.

124. Janes K, Wahlman C, Little JW, Doyle T, Tosh DK, Jacobson KA, et al. Spinal neuroimmune activation is independent of T-cell infiltration and attenuated by $\mathrm{A} 3$ adenosine receptor agonists in a model of oxaliplatin-induced peripheral neuropathy. Brain Behav Immun. 2015;44:91-9.

125. Meyer L, Patte-Mensah C, Taleb O, Mensah-Nyagan AG. Allopregnanolone prevents and suppresses oxaliplatin-evoked painful neuropathy: multi-parametric assessment and direct evidence. Pain. 2011;152:170-81.

126. Xu D, Zhao H, Gao H, Zhao H, Liu D, Li J. Participation of proinflammatory cytokines in neuropathic pain evoked by chemotherapeutic oxaliplatin via central GABAergic pathway. Mol Pain. 2018;14:1744806918783535

127. Salat K, Furgala A, Salat R. Interventional and preventive effects of aripiprazole and ceftriaxone used alone or in combination on oxaliplatininduced tactile and cold allodynia in mice. Biomed Pharmacother. 2019;111:882-90.

128. Niedzielska-Andres E, Mizera J, Sadakierska-Chudy A, PomiernyChamiolo L, Filip M. Changes in the glutamate biomarker expression in rats vulnerable or resistant to the rewarding effects of cocaine and their reversal by ceftriaxone. Behav Brain Res. 2019;370:111945.

129. Hajhashemi $V$, Hosseinzadeh H, Amin B. Antiallodynia and antihyperalgesia effects of ceftriaxone in treatment of chronic neuropathic pain in rats. Acta Neuropsychiatr. 2013;25:27-32

130. Fijalkowski L, Salat K, Podkowa A, Zareba P, Nowaczyk A. Potential role of selected antiepileptics used in neuropathic pain as human GABA transporter isoform 1 (GAT1) inhibitors-molecular docking and pharmacodynamic studies. Eur J Pharm Sci. 2017;96:362-72.

131. Ren X, Boriero D, Chaiswing L, Bondada S, St Clair DK, Butterfield DA. Plausible biochemical mechanisms of chemotherapy-induced cognitive impairment ("chemobrain"), a condition that significantly impairs the quality of life of many cancer survivors. Biochim Biophys Acta Mol basis Dis. 1865;2019:1088-97.

132. Cerulla Torrente N, Navarro Pastor JB, de la Osa Chaparro N. Systematic review of cognitive sequelae of non-central nervous system cancer and cancer therapy. J Cancer Surviv. 2020;14:464-82.

133. Quintao NLM, Santin JR, Stoeberl LC, Correa TP, Melato J, Costa R. Pharmacological treatment of chemotherapy-induced neuropathic pain: PPARgamma agonists as a promising tool. Front Neurosci. 2019;13:907.

134. Rutkove SB. Effects of temperature on neuromuscular electrophysiology. Muscle Nerve. 2001;24:867-82.
135. Scuteri A Galimberti A, Ravasi M, Pasini S, Donzelli E Cavaletti G et al. NGF protects dorsal root ganglion neurons from oxaliplatin by modulating JNK/Sapk and ERK1/2. Neurosci Lett. 2010;486:141-5.

136. Chiu IM, Heesters BA, Ghasemlou N, Von Hehn CA, Zhao F, Tran J, et al. Bacteria activate sensory neurons that modulate pain and inflammation. Nature. 2013;501:52-7.

137. Hu S, Huang KM, Adams EJ, Loprinzi CL, Lustberg MB. Recent developments of novel pharmacologic therapeutics for prevention of chemotherapy-induced peripheral neuropathy. Clin Cancer Res. 2019;25:6295-301.

138. Poupon L, Kerckhove N, Vein J, Lamoine S, Authier N, Busserolles J, et al. Minimizing chemotherapy-induced peripheral neuropathy: preclinical and clinical development of new perspectives. Expert Opin Drug Saf. 2015;14:1269-82.

139. Beijers AJM, Bonhof CS, Mols F, Ophorst J, de Vos-Geelen J, Jacobs EMG, et al. Multicenter randomized controlled trial to evaluate the efficacy and tolerability of frozen gloves for the prevention of chemotherapyinduced peripheral neuropathy. Ann Oncol. 2020;31:131-6.

140. Eldridge S, Guo L, Hamre J 3rd. A comparative review of chemotherapyinduced peripheral neuropathy in in vivo and in vitro models. Toxicol Pathol. 2020;48:190-201.

141. Farshchian N, Alavi A, Heydarheydari S, Moradian N. Comparative study of the effects of venlafaxine and duloxetine on chemotherapy-induced peripheral neuropathy. Cancer Chemother Pharmacol. 2018;82:787-93.

142. Barajas-Martinez HM, Hu D, Cordeiro JM, Wu Y, Kovacs RJ, Meltser H, et al. Lidocaine-induced Brugada syndrome phenotype linked to a novel double mutation in the cardiac sodium channel. Circ Res. 2008; 103:396-404.

143. van den Heuvel SAS, van der Wal SEl, Smedes LA, Radema SA, van Alfen N, Vissers KCP, et al. Intravenous lidocaine: old-school drug, new purpose-reduction of intractable pain in patients with chemotherapy induced peripheral neuropathy. Pain Res Manag. 2017;2017:8053474.

144. Piccolo J, Kolesar JM. Prevention and treatment of chemotherapy-induced peripheral neuropathy. Am J Health Syst Pharm. 2014:71:19-25.

145. Armstrong CM, Cota G. Calcium block of Na+ channels and its effect on closing rate. Proc Natl Acad Sci U S A. 1999;96:4154-7.

146. Knijn N, Tol J, Koopman M, Werter MJ, Imholz AL, Valster FA, et al. The effect of prophylactic calcium and magnesium infusions on the incidence of neurotoxicity and clinical outcome of oxaliplatin-based systemic treatment in advanced colorectal cancer patients. Eur J Cancer. 2011;47:369-74.

147. Grothey A, Nikcevich DA, Sloan JA, Kugler JW, Silberstein PT, Dentchev T, et al. Intravenous calcium and magnesium for oxaliplatin-induced sensory neurotoxicity in adjuvant colon cancer: NCCTG N04C7. J Clin Oncol. 2011:29:421-7.

148. Loprinzi CL, Qin R, Dakhil SR, Fehrenbacher L, Flynn KA, Atherton P, et al. Phase III randomized, placebo-controlled, double-blind study of intravenous calcium and magnesium to prevent oxaliplatin-induced sensory neurotoxicity (N08CB/Alliance). J Clin Oncol. 2014;32:997-1005.

149. Han CH, Khwaounjoo P, Kilfoyle DH, Hill A, McKeage MJ. Phase I druginteraction study of effects of calcium and magnesium infusions on oxaliplatin pharmacokinetics and acute neurotoxicity in colorectal cancer patients. BMC Cancer. 2013;13:495.

150. Meng J, Zhang Q, Yang C, Xiao L, Xue Z, Zhu J. Duloxetine, a balanced serotonin-norepinephrine reuptake inhibitor, improves painful chemotherapy-induced peripheral neuropathy by inhibiting activation of p38 MAPK and NF-kappaB. Front Pharmacol. 2019;10:365.

151. Zimmerman C, Atherton PJ, Pachman D, Seisler D, Wagner-Johnston N, Dakhil S, et al. MC11C4: a pilot randomized, placebo-controlled, double-blind study of venlafaxine to prevent oxaliplatin-induced neuropathy. Support Care Cancer. 2016;24:1071-8.

152. Durand JP, Deplanque G, Montheil V, Gornet JM, Scotte F, Mir O, et al. Efficacy of venlafaxine for the prevention and relief of oxaliplatininduced acute neurotoxicity: results of EFFOX, a randomized, doubleblind, placebo-controlled phase III trial. Ann Oncol. 2012;23:200-5.

153. Koukourakis MI, Simopoulos C, Minopoulos G, Patlakas G, Polychronidis $A$, Limberis $V$, et al. Amifostine before chemotherapy: improved tolerance profile of the subcutaneous over the intravenous route. Clin Cancer Res. 2003;9:3288-93. 
154. Penz M, Kornek GV, Raderer M, Ulrich-Pur H, Fiebiger W, Scheithauer W. Subcutaneous administration of amifostine: a promising therapeutic option in patients with oxaliplatin-related peripheral sensitive neuropathy. Ann Oncol. 2001;12:421-2.

155. Karlsson JOG, Andersson RG, Jynge P. Mangafodipir a selective cytoprotectant - with special reference to Oxaliplatin and its association to chemotherapy-induced peripheral neuropathy (CIPN). Transl Oncol. 2017;10:641-9.

156. Coriat R, Alexandre J, Nicco C, Quinquis L, Benoit E, Chereau C, et al. Treatment of oxaliplatin-induced peripheral neuropathy by intravenous mangafodipir. J Clin Invest. 2014;124:262-72.

157. Huang CY, Chen YL, Li AH, Lu JC, Wang HL. Minocycline, a microglial inhibitor, blocks spinal CCL2-induced heat hyperalgesia and augmentation of glutamatergic transmission in substantia gelatinosa neurons. J Neuroinflammation. 2014;11:7.

158. Robinson CR, Zhang H, Dougherty PM. Astrocytes, but not microglia, are activated in oxaliplatin and bortezomib-induced peripheral neuropathy in the rat. Neuroscience. 2014;274:308-17.

159. Pachman DR, Dockter T, Zekan PJ, Fruth B, Ruddy KJ, Ta LE, et al. A pilot study of minocycline for the prevention of paclitaxel-associated neuropathy: ACCRU study RU221408I. Support Care Cancer. 2017:25:3407-16.

160. Soliman AM, Teoh SL, Ghafar NA, Das S. Molecular concept of diabetic wound healing: effective role of herbal remedies. Mini Rev Med Chem. 2019;19:381-94

161. Miguel CA, Raggio MC, Villar MJ, Gonzalez SL, Coronel MF. Anti-allodynic and anti-inflammatory effects of 17alpha-hydroxyprogesterone caproate in oxaliplatin-induced peripheral neuropathy. J Peripher Nerv Syst. 2019;24:100-10.

162. Wang W, Xiang P, Chew WS, Torta F, Bandla A, Lopez V, et al. Activation of sphingosine 1-phosphate receptor 2 attenuates chemotherapyinduced neuropathy. J Biol Chem. 2020;295:1143-52.

163. Bruna J, Velasco R. Sigma-1 receptor: a new player in neuroprotection against chemotherapy-induced peripheral neuropathy. Neural Regen Res. 2018:13:775-8.

164. Toyama S, Shimoyama N, Ishida Y, Koyasu T, Szeto HH, Shimoyama M. Characterization of acute and chronic neuropathies induced by oxaliplatin in mice and differential effects of a novel mitochondria-targeted antioxidant on the neuropathies. Anesthesiology. 2014;120:459-73.

165. Resta F, Micheli L, Laurino A, Spinelli V, Mello T, Sartiani L, et al. Selective HCN1 block as a strategy to control oxaliplatin-induced neuropathy. Neuropharmacology. 2018;131:403-13.

166. Salat K, Furgala A, Salat R. Evaluation of cebranopadol, a dually acting nociceptin/orphanin FQ and opioid receptor agonist in mouse models of acute, tonic, and chemotherapy-induced neuropathic pain. Inflammopharmacology. 2018;26:361-74.

167. Flatters SJL, Dougherty PM, Colvin LA. Clinical and preclinical perspectives on chemotherapy-induced peripheral neuropathy (CIPN): a narrative review. Br J Anaesth. 2017;119:737-49.

168. Chlon-Rzepa G, Slusarczyk M, Jankowska A, Gawalska A, Bucki A, Kolaczkowski M, et al. Novel amide derivatives of 1,3-dimethyl-2,6-dioxopurin7-yl-alkylcarboxylic acids as multifunctional TRPA1 antagonists and PDE4/7 inhibitors: a new approach for the treatment of pain. Eur J Med Chem. 2018;158:517-33.

169. Choucry AM, Al-Shorbagy MY, Attia AS, El-Abhar HS. Pharmacological manipulation of Trk, p75NTR, and NGF balance restores memory deficit in global ischemia/reperfusion model in rats. J Mol Neurosci. 2019:68:78-90.

170. Gong G, Yin L, Yuan L, Sui D, Sun Y, Fu H, et al. Ganglioside GM1 protects against high altitude cerebral edema in rats by suppressing the oxidative stress and inflammatory response via the PI3K/AKT-Nrf2 pathway. Mol Immunol. 2018:95:91-8.

171. Defaye M, Gervason S, Altier C, Berthon JY, Ardid D, Filaire E, et al. Microbiota: a novel regulator of pain. J Neural Transm (Vienna). 2020;127:445-65.

172. Beijers AJ, Mols F, Tjan-Heijnen VC, Faber CG, van de Poll-Franse LV, Vreugdenhil G. Peripheral neuropathy in colorectal cancer survivors: the influence of oxaliplatin administration. Results from the populationbased PROFILES registry. Acta Oncol. 2015;54:463-9.

173. Derksen TM, Bours MJ, Mols F, Weijenberg MP. Lifestyle-related factors in the self-management of chemotherapy-induced peripheral neuropathy in colorectal cancer: a systematic review. Evid Based Complement Alternat Med. 2017;2017:7916031.

174. Gewandter JS, Gibbons CH, Campagnolo M, Lee J, Chaudari J, Ward $\mathrm{N}$, et al. Clinician-rated measures for distal symmetrical axonal polyneuropathy: ACTTION systematic review. Neurology. 2019;93:346-60.

175. Descoeur J, Pereira V, Pizzoccaro A, Francois A, Ling B, Maffre V, et al. Oxaliplatin-induced cold hypersensitivity is due to remodelling of ion channel expression in nociceptors. EMBO Mol Med. 2011;3:266-78.

176. Ling B, Authier N, Balayssac D, Eschalier A, Coudore F. Behavioral and pharmacological description of oxaliplatin-induced painful neuropathy in rat. Pain. 2007;128:225-34.

177. Shamban A. Safety and efficacy of facial rejuvenation with small gel particle hyaluronic acid with lidocaine and AbobotulinumtoxinA in post-chemotherapy patients: a phase IV investigator-initiated study. J Clin Aesthet Dermatol. 2014;7:31-6.

178. Gauchan P, Andoh T, Ikeda K, Fujita M, Sasaki A, Kato A, et al. Mechanical allodynia induced by paclitaxel, oxaliplatin and vincristine: different effectiveness of gabapentin and different expression of voltage-dependent calcium channel alpha(2)delta-1 subunit. Biol Pharm Bull. 2009:32:732-4.

179. Saif MW, Syrigos K, Kaley K, Isufi I. Role of pregabalin in treatment of oxaliplatin-induced sensory neuropathy. Anticancer Res. 2010;30:2927-33.

180. de Andrade DC, Jacobsen Teixeira M, Galhardoni R, Ferreira KSL, Braz Mileno P, Scisci N, et al. Pregabalin for the prevention of Oxaliplatininduced painful neuropathy: a randomized, double-blind trial. Oncologist. 2017;22:1154-e1105.

181. Salat K, Furgala A, Malikowska-Racia N. Searching for analgesic drug candidates alleviating oxaliplatin-induced cold hypersensitivity in mice. Chem Biol Drug Des. 2019;93:1061-72.

182. Higgins GA, Fletcher PJ, Shanahan WR. Lorcaserin: a review of its preclinical and clinical pharmacology and therapeutic potential. Pharmacol Ther. 2020;205:107417.

183. Smith EM, Pang H, Ye C, Cirrincione C, Fleishman S, Paskett ED, et al. Predictors of duloxetine response in patients with oxaliplatininduced painful chemotherapy-induced peripheral neuropathy (CIPN): a secondary analysis of randomised controlled trial - CALGB/ alliance 170601. Eur J Cancer Care (Engl). 2017;(2):26. https://doi.org/ 10.1111/ecc.12421.

184. Smith EM, Pang H, Cirrincione C, Fleishman S, Paskett ED, Ahles T, et al. Effect of duloxetine on pain, function, and quality of life among patients with chemotherapy-induced painful peripheral neuropathy: a randomized clinical trial. JAMA. 2013;309:1359-67.

185. Hershman DL, Lacchetti C, Dworkin RH, Lavoie Smith EM, Bleeker J, Cavaletti G, et al. Prevention and management of chemotherapyinduced peripheral neuropathy in survivors of adult cancers: American Society of Clinical Oncology clinical practice guideline. J Clin Oncol. 2014;32:1941-67.

186. Guillaumot MA, Cerles O, Bertrand HC, Benoit E, Nicco C, Chouzenoux $S$, et al. Oxaliplatin-induced neuropathy: the preventive effect of a new super-oxide dismutase modulator. Oncotarget. 2019;10:6418-31.

187. Qin $Y$, Iwase A, Murase T, Bayasula, Ishida C, Kato N, et al. Protective effects of mangafodipir against chemotherapy-induced ovarian damage in mice. Reprod Biol Endocrinol. 2018;16:106.

188. Glimelius B, Manojlovic N, Pfeiffer P, Mosidze B, Kurteva G, Karlberg $M$, et al. Persistent prevention of oxaliplatin-induced peripheral neuropathy using calmangafodipir (PledOx((R))): a placebo-controlled randomised phase II study (PLIANT). Acta Oncol. 2018;57:393-402.

189. Boyette-Davis J, Dougherty PM. Protection against oxaliplatin-induced mechanical hyperalgesia and intraepidermal nerve fiber loss by minocycline. Exp Neurol. 2011;229:353-7.

190. Kelley MR, Wikel JH, Guo C, Pollok KE, Bailey BJ, Wireman R, et al. Identification and characterization of new chemical entities targeting Apurinic/Apyrimidinic endonuclease 1 for the prevention of chemotherapy-induced peripheral neuropathy. J Pharmacol Exp Ther. 2016:359:300-9

191. Janes K, Little JW, Li C, Bryant L, Chen C, Chen Z, et al. The development and maintenance of paclitaxel-induced neuropathic pain require activation of the sphingosine 1-phosphate receptor subtype 1. J Biol Chem. 2014;289:21082-97. 
192. Zhang L, Wang H. FTY720 inhibits the Nrf2/ARE pathway in human glioblastoma cell lines and sensitizes glioblastoma cells to temozolomide. Pharmacol Rep. 2017:69:1186-93.

193. Dorsey SG, Kleckner IR, Barton D, Mustian K, O'Mara A, St Germain D, et al. The National Cancer Institute clinical trials planning meeting for prevention and treatment of chemotherapy-induced peripheral neuropathy. J Natl Cancer Inst. 2019;111:531-7.

194. Bruna J, Videla S, Argyriou AA, Velasco R, Villoria J, Santos C, et al. Efficacy of a novel Sigma-1 receptor antagonist for Oxaliplatin-induced neuropathy: a randomized, double-blind, placebo-controlled phase lla clinical trial. Neurotherapeutics. 2018;15:178-89.

195. Potenzieri A, Riva B, Rigolio R, Chiorazzi A, Pozzi E, Ballarini E, et al. Oxaliplatin-induced neuropathy occurs through impairment of haemoglobin proton buffering and is reversed by carbonic anhydrase inhibitors. Pain. 2020;161:405-15.

196. Nativi C, Gualdani R, Dragoni E, Di Cesare Mannelli L, Sostegni S, Norcini $M$, et al. A TRPA1 antagonist reverts oxaliplatin-induced neuropathic pain. Sci Rep. 2013;3:2005.

197. Yehia R, Saleh S, El Abhar H, Saad AS, Schaalan M. L-carnosine protects against Oxaliplatin-induced peripheral neuropathy in colorectal cancer patients: a perspective on targeting Nrf-2 and NF-kappaB pathways. Toxicol Appl Pharmacol. 2019:365:41-50.

198. Wang DS, Wang ZQ, Chen G, Peng JW, Wang W, Deng YH, et al. Phase III randomized, placebo-controlled, double-blind study of monosialotetrahexosylganglioside for the prevention of oxaliplatin-induced peripheral neurotoxicity in stage II/III colorectal cancer. Cancer Med. 2020;9:151-9.

199. Yang S, Chang MC. Effect of repetitive transcranial magnetic stimulation on pain management: a systematic narrative review. Front Neurol. 2020;11:114.

200. Maindrault-Goebel F, Tournigand C, Andre T, Carola E, Mabro M, Artru $P$, et al. Oxaliplatin reintroduction in patients previously treated with leucovorin, fluorouracil and oxaliplatin for metastatic colorectal cancer. Ann Oncol. 2004;15:1210-4.

201. Yamamoto S, Yamashita T, Ito M, Caaveiro JMM, Egashira N, TozakiSaitoh $\mathrm{H}$, et al. New pharmacological effect of fulvestrant to prevent oxaliplatin-induced neurodegeneration and mechanical allodynia in rats. Int J Cancer. 2019:145:2107-13.
202. Cerles O, Benoit E, Chereau C, Chouzenoux S, Morin F, Guillaumot $M A$, et al. Niclosamide inhibits Oxaliplatin neurotoxicity while improving colorectal cancer therapeutic response. Mol Cancer Ther. 2017;16:300-11.

203. Al-Massri KF, Ahmed LA, El-Abhar HS. Mesenchymal stem cells in chemotherapy-induced peripheral neuropathy: a new challenging approach that requires further investigations. J Tissue Eng Regen Med. 2020;14:108-22.

204. Shiragami R, Murata S, Kosugi C, Tezuka T, Yamazaki M, Hirano A, et al. Enhanced antitumor activity of cerulenin combined with oxaliplatin in human colon cancer cells. Int J Oncol. 2013;43:431-8.

205. Krishnan AV, Goldstein D, Friedlander M, Kiernan MC. Oxaliplatininduced neurotoxicity and the development of neuropathy. Muscle Nerve. 2005;32:51-60.

206. Toume K, Hou Z, Yu H, Kato M, Maesaka M, Bai Y, et al. Search of antiallodynic compounds from Plantaginis Semen, a crude drug ingredient of Kampo formula "Goshajinkigan". J Nat Med. 2019;73:761-8.

207. Cheng X, Huo J, Wang D, Cai X, Sun X, Lu W, et al. Herbal medicine AC591 prevents Oxaliplatin-induced peripheral neuropathy in animal model and cancer patients. Front Pharmacol. 2017:8:344.

208. Zhang QY, Wang FX, Jia KK, Kong LD. Natural product interventions for chemotherapy and radiotherapy-induced side effects. Front Pharmacol. 2018:9:1253.

209. Wu BY, Liu CT, Su YL, Chen SY, Chen YH, Tsai MY. A review of complementary therapies with medicinal plants for chemotherapy-induced peripheral neuropathy. Complement Ther Med. 2019;42:226-32.

210. Andrews NA, Latremoliere A, Basbaum Al, Mogil JS, Porreca F, Rice ASC, et al. Ensuring transparency and minimization of methodologic bias in preclinical pain research: PPRECISE considerations. Pain. 2016;157:901-9.

211. Mogil JS. Sex differences in pain and pain inhibition: multiple explanations of a controversial phenomenon. Nat Rev Neurosci. 2012;13:859-66.

\section{Publisher's Note}

Springer Nature remains neutral with regard to jurisdictional claims in published maps and institutional affiliations.
Ready to submit your research? Choose BMC and benefit from:

- fast, convenient online submission

- thorough peer review by experienced researchers in your field

- rapid publication on acceptance

- support for research data, including large and complex data types

- gold Open Access which fosters wider collaboration and increased citations

- maximum visibility for your research: over $100 \mathrm{M}$ website views per year

At BMC, research is always in progress.

Learn more biomedcentral.com/submissions 